\title{
Optimal Interpolation scheme to generate Reference Crop Evapotranspiration
}

\author{
Miquel Tomas-Burguera ${ }^{\mathrm{a}, *}$, Santiago Beguería ${ }^{\mathrm{a}}$, Sergio Vicente-Serrano ${ }^{\mathrm{b}}$, \\ Marco Maneta ${ }^{c}$ \\ ${ }^{a}$ Estación Experimental de Aula Dei, Consejo Superior de Investigaciones Científicas \\ (EEAD-CSIC), Avda. Montañana 1005, Zaragoza, E-50059, Spain \\ ${ }^{b}$ Instituto Pirenaico de Ecologia, Consejo Superior de Investigaciones Científicas \\ (IPE-CSIC), Avda. Montañana 1005, Zaragoza, E-50059, Spain \\ ${ }^{c}$ Department of Geosciences, University of Montana, Missoula, Montana, USA
}

\section{Abstract}

1 We used an Optimal Interpolation (OI) scheme to generate a reference crop 2 evapotranspiration $\left(E T_{o}\right)$ grid, forcing meteorological variables, and their re3 spective error variance in the Iberian Peninsula for the period 1989-2011. To

4 perform the OI we used observational data from the Spanish Meteorological 5 Agency (AEMET) and outputs from a physically-based climate model. To com6 pute $E T_{o}$ we used five OI schemes to generate grids for the five observed climate 7 variables necessary to compute $E T_{o}$ using the FAO-recommended form of the

$s$ Penman-Monteith equation (FAO-PM). The granularity of the resulting grids

9 are less sensitive to variations in the density and distribution of the observa10 tional network than those generated by other interpolation methods. This is

11 because our implementation of the OI method uses a physically-based climate 12 model as prior background information about the spatial distribution of the 13 climatic variables, which is critical for under-observed regions. This provides 14 temporal consistency in the spatial variability of the climatic fields. We also 15 show that increases in the density and improvements in the distribution of the 16 observational network reduces substantially the uncertainty of the climatic and

$17 E T_{o}$ estimates. Finally, a sensitivity analysis of observational uncertainties and network densification suggests the existence of a trade-off between quantity and quality of observations.

Keywords: reference crop evapotranspiration database, Optimal

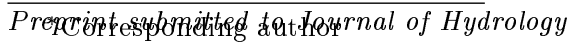


Interpolation, Uncertainty estimation, Regional Climate Model, Weather stations

\section{Introduction}

Estimations of the atmospheric evaporative demand (AED) are critical for understanding and diagnosing imbalances in the hydrologic supply and demand systems of a region. Of the available methods to estimate AED, the Food and Agriculture Organization recommended form of the Penman-Monteith equation (FAO-PM $E T_{o}$ ) is considered the best and most reliable one. The FAO-PM is a modification of the physically-based Penman-Monteith equation proposed in the FAO-56 manual (Allen et al., 1998), and has been shown to outperform other methods under a wide range of conditions. However, this method is data intensive, requiring information on air temperature, relative humidity, solar radiation, and wind speed. Simultaneous information on all these variables is often unavailable at monitored locations used for regional AED analysis.

Alternatives to obtain $E T_{o}$ estimates using less data-demanding models exist, often only requiring information on air temperature (e.g. Blaney and Criddle, 1950; Priestley and Taylor, 1972; Hargreaves and Samani, 1985). However, as Irmak et al. (2012) and McVicar et al. (2012) pointed out, the information carried by the additional meteorological variables required by the FAO-PM method are critical to obtain reliable $E T_{o}$ estimates. Hence, it is important to find a methodology that permits the generalization of the FAO-PM calculations to locations for which full information on meteorological conditions is not available. A first attempt at this generalization was included in the FAO-56 manual

(Allen et al., 1998), recommending a methodology to estimate missing data using stationary relationships between temperature and other variables. This method, hereinafter referred to as FAO-PMT, is however not devoid of problems due to the assumption of stationarity in the relationship between meteorological variables.

An alternative approach consists in using spatial interpolation to estimate 
47 the value of missing variables at the desired locations using data from nearby

48 stations, an option that Tomas-Burguera et al. (2017) showed to perform better

49 than FAO-PMT or other simplified models such as Hargreaves and Samani, at

50 least in the Iberian Peninsula (IP). This methodology have been tested in other

51 regions, such as Greece (Mardikis et al., 2005), China (McVicar et al., 2007),

52 Austria (Haslinger and Bartsch, 2016), or Great Britain (Robinson et al., 2017).

53 The last two efforts resulted in the development of high spatial resolution $(1 \mathrm{~km})$

54 datasets for these countries.

55 Also in Britain, Prudhomme and Williamson (2013) tested the use of HadRM3-

56 Q0 to quantify potential evapotranspiration and compared it against the Me-

57 teorological Office Rainfall and Evaporation Calculation System (MORECS)

58 observational grid. In the Conterminous United States, Abatzoglou (2013) con-

59 structed a FAO-PM-based $E T_{o}$ dataset derived from his $4 \mathrm{~km}$ resolution daily

60 downscaling of meteorological variables. At a much coarser spatial resolution,

61 the Climate Research Unit (CRU) TS dataset also offers an estimation of the

62 FAO-PM ET $T_{o}$ with global coverage (Harris et al., 2014).

63 While gridded datasets based on spatial interpolation methods are easy to

64 implement, the quality of the results is highly dependent on the spatial density

65 of the observational dataset used for interpolation. The minimum necessary

66 density of the observational network capable of resolving the meteorological field

67 depends on the spatial variability of the meteorological variable, and smoothing

68 of the meteorological field occurs when the observational network is sparse.

69 This smoothing is exacerbated in regions of complex terrain (Silverman and

7o Maneta, 2016). Moreover, geostatistical interpolation methods often rest on the

71 assumption that the spatial model (the semivariogram) is spatially stationary,

72 an assumption that is not valid in many practical situations, and specially over

73 rugged regions with sparse observational coverage.

74 The use of climate grids derived from physically-based climate models is

75 an alternative that overcome some of the problems of interpolation methods.

${ }_{76}$ These models, which are commonly used in climatological and meteorologi-

77 cal studies, have several main advantages: the computed meteorological grids 
have homogeneous and consistent temporal and spatial coverage, they capture the dependence (covariance) between climatic variables, and they maintain the physical spatial coherence of the field, taking into account the influence of topography on the meteorological variables and reducing the spatial smoothing that is characteristic of classic interpolation methods. There are many examples of the use of meteorological outputs from climatologic models to calculate AED. Ishak et al. (2010) used NCAR/Penn State Mesoscale Model Version 5 (MM5) to downscale ERA-40 (European Centre for Medium-Range Weather Forecasts Re-analysis) (Uppala et al., 2005) for estimating $E T_{o}$ in a catchment of southwest England. Similarly, Srivastava et al. (2013) compared the performance of ERA-INTERIM (Dee et al., 2011) and National Centers for Environmental Prediction(NCEP)/National Center for Atmospheric Research(NCAR) (Kalnay et al., 1996) reanalysis data downscaled through the Weather Research and Forecasting model (WRF) to estimate $E T_{o}$. Strong et al. (2017) tested the use of WRF to estimate $E T_{o}$ in Utah, comparing the results against the Gridded Evapotranspiration estimation (GridET) framework (Lewis and Allen, 2016) and obtaining a good performance. Despite its advantages, the use of physically-based climate models data to estimate $E T_{o}$ also presents important issues. The presence of a bias is very common, which is the reason why a bias correction step using ground weather station data is compulsory in forecasting models. Also, most climatologic model products have a coarse resolution and some variables, such as wind speed, are often poorly estimated or carry high uncertainties.

A third alternative is to use a mixture of distinct sources of data for estimating $E T_{o}$. For instance, Hart et al. (2009) developed a system to estimate $E T_{o}$ in California by using weather station data and satellite-based estimates of radiation. Martins et al. (2017) used meteorological fields from a reanalysis at $0.5^{\circ}$ of spatial resolution to estimate $E T_{o}$, but without the bias correction process conducted by Sheffield et al. (2006) on this dataset.

The different studies described above use the FAO-PM approach to generate $E T_{o}$ estimates, but do not provide a formal quantification of their uncer- 
tainty. Studies that take into account the uncertainty of $E T_{o}$ estimations look at it mostly as the variation in an ensemble of models (Kay and Davies, 2008; Kingston et al., 2009; Hosseinzadehtalaei et al., 2016), and do not consider the uncertainty of individual members of the ensemble. Unfortunately, the variance of a model ensemble reflects the uncertainty associated with a (finite) set of model architectures, and does not necessarily reflect the quality of each ensemble member, which is critical to interpret patterns emerging form the analysis of individual grids. For instance, Brohan et al. (2006) and Mortice et al. (2012) proposed and evaluated distinct methodologies to quantify the uncertainty in the HadCRUT3 and HadCRUT4 datasets, and used this information to evaluate the statistical significance of temporal trends analysis done on these datasets, which allowed them to eliminate non-significant trends from further analysis and interpretation.

The quantification of the uncertainty around interpolated climatologic estimates is specially important when interpolation is based on an inhomogeneous or time-changing network of observations. Variations over time in the uncertainty of the reconstructed climatologic field reflects variations in the quality of the observational network. For instance, changes in the number or location of stations in the network can have important effects on the spatial variance of an interpolated grid. An analysis of the variance in a time series of these grids may yield trends easily attributable to a climate processes if information on the uncertainty of the estimates is not available. Beguería et al. (2016) argued that this may be one of the most important handicaps of the application of spatial interpolation techniques for climatologic studies.

Densifications and reorganizations of regional climatologic networks are very common. For example, the deployment of automatic weather stations in Spain accelerated dramatically during the last decade, increasing the availability of data for the estimation of $E T_{o}$. A few decades back, only weather stations from the principal network (approximately 100) measured the variables required to compute $E T_{o}$ (Azorín-Molina et al., 2015), while currently more than 700 weather stations are collecting and providing near real time data on these vari- 
ables. Since the spatial distribution of AED is a quantity difficult to measure directly, studies seeking to identify spatial-temporal trends in AED will rely on $E T_{o}$ grids reconstructed using the FAO-PMT approximation, which in turn relies on information from weather stations. Minimizing and controlling the impact of the configuration of the observational network on the resulting grid is important to avoid miss-interpreting statistical artifacts as a real climatologic process.

Beyond the increasing availability of observational data for climatologic studies, climatologic fields from new physically-based climate models at high spatial resolution have become available thanks to international projects like Coordinated Regional climate Downscaling Experiment (CORDEX) (Giorgi et al., 2009). These models often cover a period starting in 1979 similar to the ERAINTERIM reanalysis product (Dee et al., 2011). The advantage of these products is that they reconstruct climatological fields that are based on atmospheric physics and largely independent from ground observations, which overcomes some of the disadvantages of interpolated grids.

Unprecedented data availability and access to computational power facilitate the use of data fusion techniques to obtain improved estimates of $E T_{o}$. Here we propose to use data assimilation methods to combine information from ground observatories and from physically-based climate models to produce improved climatic and $E T_{o}$ grids. The variance of the resulting grids is less sensitive to the number of available stations in the observational network, while ensuring that the grid from climate models are conditioned by actual observations. In addition, an estimation of their mean error is also provided as a natural by-product of the method. Specifically, our methodology is based on Optimal Interpolation (OI), which has been extensively used in the analysis of weather forecasts, in climatology and in oceanography (e.g. Reynolds et al., 2002; Ruiz-Arias et al., 2015; Lussana, 2017). OI is a minimum variance estimator that is easy to implement and that takes into account observational and model uncertainties in the final estimates.

The objective of this paper is to describe the generation of a grid of $E T_{o}$ 
over the IP. This grid maximizes the use of all available data while controlling the uncertainty and statistical stability of the resulting grid. To achieve this, we first used ground observations and a regional climate model within an OI scheme to generate gridded estimates and standard errors of each individual meteorological input variable needed to calculate the FAO-PM $E T_{o}$. Then we used this information with the FAO-PM equation to obtain the optimal $E T_{o}$ estimate. To quantify the uncertainty of the gridded $E T_{o}$, the errors from each individual gridded input variable were propagated through the FAO-PM equation using a first order method. We then analyzed the resulting grids to assess if it reduces some of the problems detected in standard interpolation methods such as kriging.

\section{Dataset}

Daily meteorological data on maximum $\left(T_{\max }\right)$ and minimum temperature $\left(T_{\min }\right)$, relative humidity $(R H)$, wind speed $(W)$ and sunshine duration $(S D)$ (as the best available surrogate for solar radiation, which is poorly measured in Spain, (Sanchez-Lorenzo et al., 2013)) from 1989 to 2011 was provided by the Spanish meteorological agency (AEMET). A quality control process was implemented at daily time-scale (Tomas-Burguera et al., 2016) prior to the aggregation to monthly scales following the recommendation of the World Meteorological Organization (WMO, 1989), using only weather stations with more than 12 months of data. The length of the available record varied between variables and the number of stations were different for each variable and varied over time. A substantial increase in the number of stations recording $R H$ and $W$

is noticeable toward the end of the study period, as previously highlighted by 5 Vicente-Serrano et al. (2014) and Azorin-Molina et al. (2016), respectively. Table 1 summarizes the number of weather stations available after quality control. The highest number of weather stations corresponded to temperature (the same number of weather stations was available for $T_{\min }$ and $T_{\max }$ ) and the minimum to $S D$. No observed meteorological data was used for Portugal. 


\begin{tabular}{lll}
\hline Variable & Number of weather stations & Simultaneous maximum \\
\hline Temperature & 3187 & 1871 \\
Relative humidity & 756 & 633 \\
Wind speed & 659 & 525 \\
Sunshine duration & 131 & 104 \\
\hline
\end{tabular}

Table 1: Number of weather stations

The regional climate model (RCM) that we used in this study was HIRHAM version 5 (Christensen et al., 2006), which dynamically downscales the ERAINTERIM model (Dee et al., 2011) for the CORDEX project (Giorgi et al., 2009). From this model we extracted gridded outputs for $T_{\max }, T_{\min }, R H, W$, and $S D$, which are the same variables in the observational dataset. The grids covered the IP at monthly temporal resolution and $0.11^{\circ}$ spatial resolution for the period 1989-2011. Additionally, a digital elevation model obtained from the Spanish National Geographic Institute (IGN) was used to evaluate the mean elevation of each grid cell.

The study area, and the location of the main geographic features referenced in this paper, are presented in Fig. 1

\section{Methods}

The meteorological variables described above were used as inputs to the Penman Monteith equation to obtain $E T_{o}$. We used the form of the Penman Monteith equation recommended by FAO (Allen et al., 1998). To construct the $E T_{o}$ grid from information obtained at meteorological sites we used the method of OI, a data assimilation technique commonly used in the atmospheric and ocean sciences. The application of the OI algorithm to generate the $E T_{o}$ grid can be done in two different ways:

1. calculate the $E T_{o}$ using FAO-PM at each point with available observations and then optimally interpolate the resulting $E T_{o}$ values to generate the grid; and 
2. optimally interpolate the five individual meteorological fields needed to calculate $E T_{o}$, generate five interpolated grids, one per variable, and then calculate $E T_{o}$ using the FAO-PM equation in the complete grids.

Previous work (Tomas-Burguera et al., 2017) has shown that although more computationally demanding, the latter approach is preferable, at least in the IP, and therefore we chose it in this study. Since in option 2) $E T_{o}$ is not directly optimally interpolated, the uncertainty of each individual meteorological field needs to be propagated through the FAO-PM equation to calculate the final uncertainty of the $E T_{o}$ estimates.

\subsection{ETo estimation}

Allen et al. (1998) adapted the Penman-Monteith equation to a reference crop of height $0.12 \mathrm{~m}$, a surface resistance of $70 \mathrm{~s} \mathrm{~m}^{-1}$ and an albedo of 0.23 :

$$
E T_{o}=\frac{0.408 * \Delta *\left(R_{n}-G\right)+\gamma *\left(\frac{900}{T+273}\right) * U_{2} *\left(e_{s}-e_{a}\right)}{\Delta+\gamma *\left(1+0.34 * U_{2}\right)}
$$

where $R_{n}$ is the net radiation at the crop surface $\left(M J m^{-2} d a y^{-1}\right), G$ is the soil heat flux density $\left(M J m^{-2} d a y^{-1}\right), T$ is the mean air temperature at $2 \mathrm{~m}$ $\left({ }^{\circ} \mathrm{C}\right), U_{2}$ is the wind speed at $2 \mathrm{~m}\left(m s^{-1}\right), e_{s}$ is the saturation vapor pressure $(k P a), e_{a}$ is the actual vapor pressure $(k P a), e_{s}-e_{a}$ is the saturation vapor pressure deficit $(k P a), \Delta$ is the slope of the vapor pressure curve $\left(k P a{ }^{\circ} C^{-1}\right)$ and $\gamma$ is the psychrometric constant $\left(k P a{ }^{\circ} C^{-1}\right)$. The value 0.408 is used to convert from $M J m^{-2} d a y^{-1}$ units to $\mathrm{kg} \mathrm{m}^{-2} \mathrm{day}^{-1}$ (alternatively: $\mathrm{mm} d a y^{-1}$ ).

Some of the previous variables are not directly measured, but according to the procedure defined in Allen et al. (1998) they could be estimated using the meteorological data at hand. Specifically, $T, R_{n}, G, e_{s}, e_{a}$ and $\Delta$ were estimated using $S D, T_{\max }, T_{\min }$ and $R H$. The variable $U_{2}$ coincided with $W$.

The equation (Eq. 1) is usually known as FAO-PM and is the equation we used to estimate $E T_{o}$ at the monthly time-step. When necessary, we shall distinguish between $E T_{o}$ computed using RCM data, $\mathbf{E T}_{\mathbf{o}}^{\mathbf{b}}$, and from OI data, ET $_{\mathbf{o}}^{\mathbf{a}}$. 


\subsection{Optimal Interpolation}

The OI equations can be easily derived as a variational problem with the goal of finding a vector of estimates that minimizes the total error variance of the field being estimated (Wikle and Berliner, 2006). The estimator is unbiased and linear between the observations and a first guess (a priori estimation) of the field. The general form of the OI equations takes the form:

$$
\begin{gathered}
\mathbf{x}_{v}^{\mathbf{a}}=\mathbf{x}_{v}^{\mathbf{b}}+\mathbf{K}_{v}\left(\mathbf{y}_{v}-\mathbf{H}_{v} \mathbf{x}_{v}^{b}\right) \\
\mathbf{K}_{v}=\left(\mathbf{P}_{v} \mathbf{H}_{v}^{\top}\right)\left(\mathbf{H}_{v} \mathbf{P}_{v} \mathbf{H}_{v}^{\top}+\mathbf{R}_{v}\right)^{-1} \\
\mathbf{P}_{v}^{+}=\left(\mathbf{I}-\mathbf{K}_{v} \mathbf{H}_{v}\right) \mathbf{P}_{v}
\end{gathered}
$$

where the subscript $v$ refers to each one of the meteorological variables used in the Penman Monteith equation $\left(T_{\max }, T_{\min }, R H, W, S D\right)$ and that we are interested in optimally interpolating. Notice that we have an independent OI process for each variable; $\mathbf{x}^{\mathbf{a}}$ is a vector of length $m$ representing the final interpolated variable, i.e. the OI estimator for the variable $v ; \mathrm{x}^{\mathbf{b}}$ is a vector of length $m$ representing the background or first guess of the field (in our case the $\mathrm{RCM}$ ); $\mathbf{y}$ is a vector of length $n$ of observations (in our case the instrumental data from the weather stations); $\mathbf{H}(n \times m)$ is a sparse binary matrix to project the background data into the observation space; $\mathbf{K}(m \times n)$ is the Kalman gain matrix that provides the optimal linear combination between the background and the observations; $\mathbf{P}(m \times m)$ and $\mathbf{R}(n \times n)$ are the error covariance matrices for the background and the observations, respectively; $\mathbf{P}^{+}(m \times m)$ is the error covariance matrix of $\mathbf{x}^{\mathbf{a}}$; and $\mathbf{I}(m \times m)$ is the identity matrix. Finally, $m$ is the grid size, which is invariant and in our case has 3930 cells, and $n$ is the number of grid cells with observations, which varies with each variable and time step.

The results are sensitive to the values prescribed for $\mathbf{P}$ and $\mathbf{R}$, but these quantities are difficult to estimate because the amount of background (process) uncertainty associated and the observational errors are typically unknown. The parameterization of these quantities is explained later in this section.

OI assumes that both the background and the observations are unbiased with normally distributed errors: 


$$
\begin{array}{ll}
\mathbf{x}_{v}^{\mathbf{b}}=\mathbf{x}_{v}^{\mathbf{t}}+\mathbf{g}_{v}, & \mathbf{g}_{v} \sim \mathcal{N}\left(\mathbf{0}, \mathbf{P}_{v}\right) \\
\mathbf{y}_{v}=\mathbf{y}_{v}^{\mathbf{t}}+\mathbf{e}_{v}, & \mathbf{e}_{v} \sim \mathcal{N}\left(\mathbf{0}, \mathbf{R}_{v}\right)
\end{array}
$$

where $\mathbf{x}^{\mathbf{t}}$ is the (unknown) true value of the meteorological field, $\mathbf{y}^{\mathbf{t}}$ is the (unknown) true value at grid cells with observations, and $\mathbf{g}$ and $\mathbf{e}$ are random errors normally distributed with mean 0 and covariance matrices $\mathbf{P}$ and $\mathbf{R}$, respectively. $\mathbf{P}$ and $\mathbf{R}$ are assumed to be independent from each other, a condition that is critical for the correct performance of the OI.

In this study, the background estimates of the meteorological fields $\left(\mathbf{x}_{v}^{\mathbf{b}}\right.$ and $\mathbf{P}_{v}$ ) were obtained from the RCM. We assume that the climatologic variables of each month are random variables with stationary variance, and that each month in the record is a sample. Following this assumption, and in the absence of better information, the inter-annual variance of a meteorological variable is the most natural approximation of the uncertainty about the estimation of such variable in a given specific month and year. In other words, variables with more variance have higher uncertainty. This is further discussed in section 4.5.

The matrix $\mathbf{P}_{\mathbf{j}_{v}}$ for each of the 12 months $j$ in the record of $N$ years can then be calculated as:

$$
\mathbf{P}_{\mathbf{j}_{v}}=\frac{1}{N-1}\left(\mathbf{x}_{\mathbf{j}_{v}}^{\mathbf{b}}-\mathbf{1} \overline{\mathbf{x}_{\mathbf{j}_{v}}^{\mathbf{b}}}\right)^{\boldsymbol{\top}}\left(\mathbf{x}_{\mathbf{j}_{v}}^{\mathbf{b}}-\mathbf{1} \overline{\mathbf{x}_{\mathbf{j}_{v}}^{\mathbf{b}}}\right), \text { for } \mathbf{j}=\{1, \ldots, 12\}
$$

where $\mathbf{x}_{\mathbf{j}_{v}}^{\mathbf{b}}$ is a matrix where each column is a cell in the grid and each row is a simulated month $j$ in the record, $\mathbf{1}$ is a column vector of ones of size $N$, and $\overline{\mathbf{x}_{\mathbf{j}_{v}}^{\mathbf{b}}}$ is a column vector with the monthly means of each cell obtained by averaging the columns of $\mathbf{x}_{\mathbf{j}_{v}}^{\mathbf{b}}$.

For simplicity, the use of the subscript $v$ to refer to the different meteorological variables is suppressed from now on. When necessary, explicit references to the variables will be used. 


\subsubsection{Observation uncertainty, $\mathbf{R}$}

Unlike RCM outputs, which provide meteorological estimates that are representative at the grid-cell scale, ground observations at a location in a cell can be considered a sample of the probability distribution of the variable within that cell. This distribution is determined by the spatial variability of the meteorological variable within the cell, which is unknown. We calculated the observed estimates at each grid cell where at least one weather observation exists, and interpreted $\mathbf{R}$ as representing the uncertainty associated with the point-to-grid conversion (representational uncertainty). In other words, $\mathbf{R}$ is the uncertainty that the actual measured location is representative of the average conditions of the entire cell. Representational errors are assumed to be independent, i.e. $\mathbf{R}$ is a diagonal matrix and therefore error covariances between stations are zero. Note that since $\mathbf{R}$ is diagonal, the combination of observational information imposed by $\mathbf{K}$ on the optimally interpolated grid (eq. 2) is mostly controlled by the covariances of $\mathbf{P}$ (i.e. interpolation relies on the spatial covariance of the climatologic process as described by the physics of the model). Without a direct way to calculate the representational error we chose $\mathbf{R}$ to be inversely proportional to the number of stations in the monitored cell:

$$
\mathbf{R}=\mathbf{I} \beta / n_{o b s}
$$

where $\mathbf{I}$ is the identify matrix of order $n, \beta$ is a fixed scaling parameter that controls the magnitude of $\mathbf{R}$ and that will be used to test the impact of representational errors on the results, and $n_{o b s}$ is the number of observatories used in the estimation of $\mathbf{y}$. The higher the number of stations in a cell, the lower the representational uncertainty.

Guided by our experience, we initially fixed $\beta$ at 4.5 for $T_{\max }$ and $T_{\min }, 9$ for $R H$ and $W$ and 0.9 for $S D$. To investigate the impact of scaling $\mathbf{R}$ on the results, we performed a sensitivity analysis on the choice of $\beta$ as described in section 3.4. 


$$
\left(\mathbf{J}_{E T_{o}}\right)=\left[\begin{array}{lllll}
\frac{\partial E T_{o}}{\partial T_{\max }} & \frac{\partial E T_{o}}{\partial T_{\min }} & \frac{\partial E T_{o}}{\partial H R} & \frac{\partial E T_{o}}{\partial W} & \frac{\partial E T_{o}}{\partial S D}
\end{array}\right]
$$

\subsection{Uncertainty Estimation}

To estimate the uncertainty of $\mathbf{E T}_{\mathbf{o}}^{\mathbf{a}}$ we propagated the uncertainty of each one of the meteorological variables through the FAO-PM equation using a firstorder method. For this we linearized the FAO-PM equation to obtain its Jacobian matrix $\mathbf{J}_{E T_{o}}$ and used it to propagate the covariance of the meteorological variables. For a specific location (grid-cell) $k$, we have:

$$
\left(\boldsymbol{\sigma}_{E T_{o}}^{\mathbf{a}}\right)_{k}^{2}=\left(\mathbf{J}_{E T_{o}}\right)_{k} \mathbf{Q}_{k}\left(\mathbf{J}_{E T_{o}}\right)_{k}^{\top}
$$

where $\mathbf{Q}_{k}$ is the covariance matrix of the variables at location $k$. The Jacobian was analytically calculated with the following form:

Assuming independence of errors between the meteorological variables, and using only the diagonal values (variances) of $\mathbf{P}^{+}$, i.e. $\sigma^{2} \equiv \operatorname{diag}\left(\mathbf{P}^{+}\right)$, the total error covariance matrix at location $k$ is diagonal:

$$
\mathbf{Q}_{k}=\left[\begin{array}{ccccc}
\left(\boldsymbol{\sigma}_{T_{\max }}^{2}\right)_{k} & 0 & 0 & 0 & 0 \\
0 & \left(\boldsymbol{\sigma}_{T_{\min }}^{2}\right)_{k} & 0 & 0 & 0 \\
0 & 0 & \left(\boldsymbol{\sigma}_{H R}^{2}\right)_{k} & 0 & 0 \\
0 & 0 & 0 & \left(\boldsymbol{\sigma}_{W}^{2}\right)_{k} & 0 \\
0 & 0 & 0 & 0 & \left(\boldsymbol{\sigma}_{S D}^{2}\right)_{k}
\end{array}\right]
$$

7 Where the subscript $k$ denotes we are using the scalar $k$ element of $\boldsymbol{\sigma}_{v}^{2}$.

The assumption of independence and the diagonal nature of $\mathbf{Q}$ permits to avoid operating with the full matrix $\mathbf{Q}$ and simplifies the propagation of errors. Under these assumptions, the uncertainty of $\mathbf{E T}_{\mathbf{o}}^{\mathbf{a}}$ can be calculated independently at each location $\mathrm{k}$ as:

$$
\begin{array}{r}
\left(\boldsymbol{\sigma}_{E T_{o}}^{\mathbf{a}}\right)_{k}^{2}=\left(\frac{\partial E T_{o}}{\partial T_{\max }}\right)_{k}^{2} *\left(\boldsymbol{\sigma}_{T_{\max }}^{2}\right)_{k}+\left(\frac{\partial E T_{o}}{\partial T_{\min }}\right)_{k}^{2} *\left(\boldsymbol{\sigma}_{T_{\min }}^{2}\right)_{k}+ \\
\left(\frac{\partial E T_{o}}{\partial H R}\right)_{k}^{2} *\left(\boldsymbol{\sigma}_{H R}^{2}\right)_{k}+\left(\frac{\partial E T_{o}}{\partial W}\right)_{k}^{2} *\left(\boldsymbol{\sigma}_{W}^{2}\right)_{k}+\left(\frac{\partial E T_{o}}{\partial S D}\right)_{k}^{2} *\left(\boldsymbol{\sigma}_{S D}^{2}\right)_{k}
\end{array}
$$




\subsection{Sensitivity analysis}

To assess the impact that the choice of $\mathbf{R}$ has on the results, we conducted multiple OI analyses using a range of values of $\beta$ to vary de magnitude of $\mathbf{R}$. For each interpolated meteorological variable, we tested four different values of this scaling parameter that evenly partitioned the range of $\mathbf{R}$ from an end member that represents high confidence in the observations $(<\mathbf{R}>\leq<\mathbf{P}>)$ to a value that represents low confidence $(<\mathbf{R}>\geq<\mathbf{P}>)$. Table 2 shows the spatial mean values of $\mathbf{P}(\langle\mathbf{P}\rangle)$, which were used as a reference to design the values to scale R. Lowest and higher values of $(\langle\mathbf{P}>)$ are selected from the 12 unique $(<\mathbf{P}>)$ monthly values. $\beta$ values are chosen to cover the range between a value lower than the lowest $(<\mathbf{P}>)$ value, and a value higher than the highest $(<\mathbf{P}>)$ value.

\begin{tabular}{lllllll} 
& \multicolumn{3}{c}{$\langle\mathbf{P}>$ values } & \multicolumn{4}{c}{$\beta$ tested values } \\
\hline Variable & Lowest value & Highest value & 1 st & 2nd & 3 rd & 4 th \\
\hline$T_{\max }$ & 1.1 & 4 & 0.9 & 3.6 & 6.3 & 9 \\
$T_{\min }$ & 1.3 & 3 & 0.9 & 3.6 & 6.3 & 9 \\
$R H$ & 28 & 48 & 9 & 36 & 63 & 90 \\
$W$ & 0.06 & 0.37 & 0.009 & 0.09 & 0.9 & 9 \\
$S D$ & 0.03 & 0.74 & 0.009 & 0.09 & 0.9 & 9 \\
\hline
\end{tabular}

Table 2: Spatial mean values of $\mathbf{P}(\langle\mathbf{P}\rangle)$ and interval of tested $\beta$ values

\subsection{Spatial correlation with Portugal}

The impact of not using weather observations over Portugal was evaluated by analyzing the spatial structure of $\mathbf{P}$, and specifically how cells with observations in Spain covary and inform climatic estimates over Portugal. Since $\mathbf{R}$ is diagonal, the spatial structure imposed by the optimal interpolation scheme is to a large extent driven by $\mathbf{P}$. To facilitate the spatial analysis, we first transformed our covariance matrices into correlation matrices. Then, we analyzed the number of grid points in Portugal that correlate with observed grid-points in Spain with a coefficient higher than 0.75. When grid cells in Portugal correlate highly with cells containing observations, then these observation can inform the 
corrections in Portugal even though they are located in Spain. During periods where correlations are lower, the quality of the estimates over Portugal decrease.

\section{Results}

\subsection{Observational dataset}

The number of instrumental observations used in the gridding process varied with time as individual stations in the network were added or decommissioned. Figure 2 presents a time series with the number of grid cells in the domain containing one or more observations for each of the meteorological variables used in the calculation of $E T_{o}$. Temperature $\left(T_{\max }\right.$ and $\left.T_{\min }\right)$ had the densest spatial coverage. The number of grid cells for which temperature data were available increased from about 1200 in the late 1980s to over 1300 in 1995. From the mid1990s, the number of stations declined steadily, and the number grid cells with temperature data was 1100-1150 toward the end of the study period. Stations that registered $R H$ and $W$ where less common at the start of analysis period. In the late 1980s, only about 100 grid cells contained information on these variables. The number of stations measuring $R H$ and $W$ increased steadily until the mid2000s, when the installation of automatic weather stations (AWS) resulted in a sharp increase in the number of grid cells containing information. On the other hand, the number of stations measuring $S D$ declined over time from about 90 stations in the late 1980s to less than 70 at the end of the study period. This decline was partly due to the obsolescence of the heliographs used to perform the measurements, which are being replaced by modern radiometers. The reason we did not include information from radiometers is that only heliographs provide a homogeneous dataset that covers the entire study period.

\subsection{Optimally interpolated climatic variables and ETo estimates}

The proposed method produces gridded fields of mean $\left(\mathrm{x}^{\mathbf{a}}\right)$ and variance $\left(\boldsymbol{\sigma}^{\mathbf{a}}\right)^{2}$ estimates for each climate variable and for $E T_{o}\left(\mathbf{E T}_{\mathbf{o}}^{\mathbf{a}}\right.$ and $\left.\left(\boldsymbol{\sigma}_{E T_{o}}^{\mathbf{a}}\right)^{2}\right)$. To illustrate the outcome of the process and provide a sense of the typical spatial distribution of the estimates and their associated uncertainty, results are 
presented for one sample month, July 1994 (Figure 3). Overall, the estimates for all meteorological variables and for $E T_{o}$ show spatial structure devoid of the interpolation artefacts often produced by other interpolation methods. The expected spatial climatologic patterns of the variables over the IP are captured, including very localized windward-leeward effects produced by the rugged physiography of mountain regions. In this sample month, the highest temperatures are located in the southern region of the peninsula and in the Ebro Valley in the northeast. High $\mathbf{x}_{R H}^{\mathbf{a}}$ values are concentrated in regions close to the coast and along corridors that extend the oceanic influence further inland. Wind speed, $\mathbf{x}_{W}^{\mathbf{a}}$, is highest in the Castilla la Mancha region (eastern Spain), and in the Ebro Valley in northeastern Spain, where high wind speeds are facilitated by the unobstructed high plateau of Castilla, and by accelerations of northern winds in the Ebro Valley due to the interaction between the orographic dipole of the Pyrenees mountain range with the morphology of the Ebro catchment (Riosalido et al., 1996).

Finally, sunny summers and the compact shape of the IP produce similar mean $\mathbf{x}_{S D}^{\mathbf{a}}$ estimates in July, with the exception of the coastal northern region where mean $\mathbf{x}_{S D}^{\mathbf{a}}$ values are significantly lower due to persistent cloud cover. The climatology described by these variables produces $\mathbf{E T}_{\mathbf{o}}^{\mathbf{a}}$ estimates that are higher in the southern region and in the Ebro valley, and lower in the north and northwest region of the peninsula. The uncertainty of these estimates, represented as the standard deviation $\boldsymbol{\sigma}^{\mathbf{a}}$, are in general low due to the relatively high number of instrumental observations available and the high spatial correlation of the variables. This is especially true for $\boldsymbol{\sigma}_{T_{\max }}^{\mathbf{a}}$ and $\boldsymbol{\sigma}_{T_{\min }}^{\mathbf{a}}$, for which typical values were lower than $0.3^{\circ} C . \sigma_{R H}^{\mathbf{a}}$ presents higher values in the southwest and northeast. This study did not use observations in Portugal, which is the reason why these variables show higher uncertainty in the west and southwestern regions of the IP. Relatively high values of $\boldsymbol{\sigma}_{W}^{\mathrm{a}}$ are present only in the regions with highest wind speeds. The northwestern and northern coastal regions, where cloud cover is most variable, result in the highest values for $\boldsymbol{\sigma}_{S D}^{\mathbf{a}}$. Because the FAO-PM equation is non-linear and concave upward, uncertainties 
423 ${ }_{444} \mathrm{x}^{\mathrm{a}}$ over time) and $\overline{\mathrm{x}^{\mathrm{b}}}$ (the same for $\mathrm{x}^{\mathrm{b}}$ ) for each climate variable and for $E T_{o}$ ${ }_{445}\left(\overline{\mathbf{E T}_{\mathbf{o}}^{\mathbf{a}}}\right.$ and $\left.\overline{\mathbf{E T}_{\mathbf{o}}^{\mathbf{b}}}\right)$, as well as their differences $\overline{\boldsymbol{\delta}}$. In general, the RCM tended to ${ }_{446}$ underestimate $T_{\max }\left(\overline{\boldsymbol{\delta}_{T_{\max }}}>0\right)$ and to overestimate $T_{\min }\left(\overline{\boldsymbol{\delta}_{T_{\min }}}<0\right)$, indi${ }_{447}$ cating that the RCM describes a shallower annual temperature range than the 448 observations. We should keep in mind, though, that the RCM output repre449 sents mean cell estimates, which are expected to have a lower variability than

are amplified in regions of high $E T_{o}$, where the function tends to have steeper derivatives.

To illustrate the typical time series generated by our method for each meteorological variable and for $\mathbf{E T}_{\mathbf{o}}^{\mathbf{a}}$. Figure 4 presents results for one sample location in central Spain. The most prominent feature of estimates for $\mathbf{x}_{T_{\max }}^{\mathbf{a}}, \mathbf{x}_{T_{\min }}^{\mathbf{a}}, \mathbf{x}_{S D}^{\mathbf{a}}$, and $\mathbf{E T}_{\mathrm{o}}^{\mathbf{a}}$ is the expected and marked seasonality with summer peaks and winter lows. An inverse seasonality affects $\mathbf{x}_{R H}^{\mathbf{a}}$, with summer lows and winter peaks, whereas $\mathbf{x}_{W}^{\mathbf{a}}$ does not show seasonality. The most interesting information in this figure is the standard deviation of the estimates $\boldsymbol{\sigma}^{\mathbf{a}}$, which shows that uncertainty has a clear dependency on time (seasonality) for all variables. In addition, $\boldsymbol{\sigma}_{R H}^{\mathbf{a}}$, and to a lesser degree $\boldsymbol{\sigma}_{W}^{\mathbf{a}}$, exhibit a marked decrease in the standard deviation of the estimates toward the last quarter of the study period, while $\boldsymbol{\sigma}_{S D}^{\mathrm{a}}$ shows a moderate increase over time. These trends are associated with variations in the number of data points used to perform the interpolation, as we will discuss later. Seasonality and trends in the uncertainty of individual climate variables are propagated to $\boldsymbol{\sigma}_{E T_{o}}^{\mathbf{a}}$, which in general also shows a clear seasonality and a decline toward the last quarter of the period.

\subsection{Comparison between $O I$ and the $R C M$}

The analysis of differences $\boldsymbol{\delta}=\mathrm{x}^{\mathbf{a}}-\mathrm{x}^{\mathbf{b}}$ between the OI and the background $\mathrm{RCM}$ is of interest for detecting possible biases in the RCM, and also to evaluate the adequacy of the observational network. Figure 5 shows $\overline{\mathrm{x}^{\mathrm{a}}}$ (the mean of the very local (point) information represented by the observations. For $R H$, the OI estimates present higher values $\left(\overline{\boldsymbol{\delta}_{R H}}>0\right)$ in the southern region of the IP, and lower values in the northern part $\left(\overline{\boldsymbol{\delta}_{R H}}<0\right)$. For $W$ the biggest differences 
453 appeared in the north-east region, specially along the Ebro Valley. Lower values

${ }_{454}$ of $S D\left(\overline{\delta_{S D}}<0\right)$ appeared in the northern region, which could be related to the presence of low level clouds not easily resolved by RCMs.

The effect of these differences is only modestly apparent in the mean $E T_{o}$ of the study period. The method corrects an $\overline{\mathbf{E T}_{\mathbf{o}}^{\mathbf{b}}}$ overestimation $\left(\overline{\boldsymbol{\delta}_{E T_{o}}}<0\right)$ in the southern region of the IP and in the Ebro Valley, and corrects an underestimation $\left(\overline{\boldsymbol{\delta}_{E T_{o}}}>0\right)$ in the northern region and mountainous areas. $\overline{\mathbf{E T}_{\mathbf{o}}^{\mathbf{a}}}$ presents higher values in the northern region and lower values in the southern region. In general, it appears that the spatial pattern of $\overline{\boldsymbol{\delta}_{E T_{o}}}$ is very similar to the pattern of $\overline{\delta_{R H}}$, suggesting that this variable is a major player in determining the spatial patterns of the atmospheric water demand in the region.

The domain-wide seasonal amount of correction is depicted in Figure 6, which presents monthly $\left\langle\overline{\mathbf{E} \mathbf{T}_{\mathbf{o}}^{\mathbf{a}}}\right\rangle$ and $\left\langle\overline{\mathbf{E} \mathbf{T}_{\mathbf{o}}^{\mathbf{b}}}\right\rangle$. In general, the mean values are similar except during spring and autumn, where $\overline{\mathbf{E T _ { \mathbf { o } } ^ { \mathbf { b } }}}$ seems to overestimate regional mean values. The figure also presents the spatial interquartile range. Here also, the largest differences between the two datasets occur during spring and autumn. During these months, the spatial variability of $\overline{\mathbf{E T}_{\mathbf{o}}^{\mathbf{a}}}$ is smaller than that represented by $\overline{\mathbf{E} \mathbf{T}_{\mathbf{o}}^{\mathbf{b}}}$.

\subsection{Impact of the number of available observations}

As described in section 4.1, the number of stations providing meteorological information varies over time, being most prominent the increase in the number of stations measuring $R H$ and $W$. In standard interpolation methods, the granularity of the resulting fields is highly dependent on the number and spatial distribution of the observational data used for interpolation. This is a problem because it also generates trends in the dispersion statistics (variance, kurtosis) of the spatial fields. We evaluate the extent to which OI reduces this problem by analyzing the impact of the number of observations on the amount of correction that our methods apply to the RCM estimates, and on the spatial variance of the corrected fields.

Figure 7 shows time series of the spatial mean of the correction applied 
483

484

to the RCM, $\left\langle\boldsymbol{\delta}_{E T_{o}}>\right.$. The differences are grouped by months to remove the seasonal cycle. While a strong variability in the mean correction is detected in some months, no trends are apparent in the time series, not even in the last quarter of the period when a sharp increase in the number of $R H$ and $W$ weather stations took place. We also analyzed if the varying number of stations used in the OI process generated temporal trends in the spatial variability of the $\mathbf{E T}_{\mathbf{o}}^{\mathbf{a}}$ field. Figure 8 shows time series of the standard deviation of the field, also grouped by months. An inspection of the figure shows that only seasonal patterns exist, and that no apparent trends can be identified that reveal an increase or decrease in the variability of the field as the number of observations used for interpolation changed over the years.

While the mean estimates did not seem sensitive to the number of stations used in the OI process, the same was not true for their uncertainty. Figure 9 show time series of the spatial mean of the uncertainty of meteorological variables $\left\langle\boldsymbol{\sigma}^{\mathbf{a}}\right\rangle$ and of $E T_{o},\left\langle\boldsymbol{\sigma}_{E T_{o}}^{\mathbf{a}}\right\rangle$. In the figure we see that $\left\langle\boldsymbol{\sigma}_{E T_{o}}^{\mathbf{a}}\right\rangle$ follows the same seasonality of the mean values, showing higher uncertainty during the summer months and lower in winter, but the overall uncertainty decreased over the years as the available information used to condition the RCM field increased. The Man-Kendall trend test (Mann, 1945; Kendall, 1975), with a significance level $\alpha=0.05$, determined that the negative trend in the mean spatial uncertainty $<\left(\boldsymbol{\sigma}_{E T_{o}}^{\mathbf{a}}\right)^{2}>$ is significant for all the months except for June (Table 1 Anex). The decrease in $\left\langle\boldsymbol{\sigma}_{E T_{o}}^{\mathbf{a}}>\right.$ seems to be most related to the sharp decrease in $\left\langle\boldsymbol{\sigma}_{R H}^{\mathbf{a}}\right\rangle$ and $\left\langle\boldsymbol{\sigma}_{W}^{\mathbf{a}}\right\rangle$ as the number of observations for these two variables increase. This occurs despite the fact that the $\left\langle\boldsymbol{\sigma}_{T_{\max }}^{\mathbf{a}}\right\rangle,\left\langle\boldsymbol{\sigma}_{T_{\min }}^{\mathbf{a}}\right\rangle$ and $<\boldsymbol{\sigma}_{S D}^{\mathbf{a}}>$ increase as the number of available observations declined. The highest uncertainty in the temperature estimates occurred during the warmest months of the year, with a secondary peak in winter for $\left\langle\boldsymbol{\sigma}_{T_{m i n}}^{\mathrm{a}}\right\rangle$. On the other hand, $<\boldsymbol{\sigma}_{W}^{\mathrm{a}}>$ and $\left\langle\boldsymbol{\sigma}_{S D}^{\mathrm{a}}>\right.$ showed higher values in winter and lower values in summer. $<\boldsymbol{\sigma}_{R H}^{\mathbf{a}}>$ showed no seasonality, having similar values throughout the year. 


\subsection{Impact of $R$}

Figures 10 and 11 present, respectively, the time series of the spatial mean of estimates for each meteorological variable, $\left\langle\mathbf{x}^{\mathbf{a}}\right\rangle$, and of the spatial mean of their associated posterior standard deviation, $\left\langle\boldsymbol{\sigma}^{\mathbf{a}}\right\rangle$, for each of the four tested $\mathbf{R}$ matrices.

In general we found that the results estimates remained robust for the range of $\mathbf{R}$ matrices tested and only $\mathbf{x}_{W}^{\mathbf{a}}$ and $\mathbf{x}_{S D}^{\mathbf{a}}$ showed relevant differences. In the case of $\mathbf{x}_{W}^{\mathbf{a}}$, differences appeared only in the first years of the study when the number of available observations was similar to those of $S D$. As the number of $W$ observations increased, the effect of $\mathbf{R}$ on $\mathbf{x}_{W}^{\mathbf{a}}$ faded out, and similar results were obtained for the different matrices. On the other hand, the sensitivity of $\mathbf{x}_{S D}^{\mathbf{a}}$ on $\mathbf{R}$ remained since the number of observations available of this variable continued to decline. This suggests the existence of an observation density threshold beyond which the impact of observation uncertainties on the OI estimation process is limited. The magnitude of $\mathbf{R}$ has a more severe impact on the spatial mean of the estimate uncertainty, $\left\langle\boldsymbol{\sigma}^{\mathbf{a}}\right\rangle$. As expected, larger $\mathbf{R}$ values resulted in larger uncertainties, with a clear dependency on the number of available observations. This effect was most clear on $\left\langle\boldsymbol{\sigma}_{R H}^{\mathbf{a}}\right\rangle$ and $\left\langle\boldsymbol{\sigma}_{W}^{\mathbf{a}}\right\rangle$, since these two variables experienced the sharpest increase in the number of observations during the study period. It is worth noting that the values of $\left.<\boldsymbol{\sigma}_{R H}^{\mathbf{a}}\right\rangle$ at the end of the period in the worst-case scenario (largest $\mathbf{R}$ ) were similar to those at the start of the period in the best-case scenario (lowest $\mathbf{R}$ ), which suggests the existence of a trade-off between the quantity and the quality of the observations.

\subsection{Portugal correlation analysis}

Figure 12 shows the results of the spatial correlation analysis over Portugal for all the variables in two contrasting months, January and July. The color in each cell indicates with how many of the 600 grid-cells over Portugal the cell has a correlation higher than 0.75. In January (winter), large areas of Spain show high correlation with Portugal. In all cases, and not surprisingly, 
542 western Spain is the most correlated region with Portugal. $T_{\max }$ and $T_{\min }$ are

543 the variables exhibiting the most extensive correlation.It is interesting that $R H$

544 and $S D$ during the month of January show a region of extensive correlation with

545 Portugal in the southern face of Pyrenees range. This is mostly explained by the

546 orographic uplift of southern winds in this region, which occur simultaneously

547 with cyclonic conditions affecting the western part of IP. on the other hand,

548 correlated areas tend to decrease in July (summer) for all variables and the

549 correlations are more spatially restricted to the western area of Spain. The

550 decrease in the extension of highly correlated areas is specially acute for $S D$,

551 which is explained by the fact that cloudiness during summer months is often

552 related to local or subregional conditions (i.e. mainly convection and sea fog

553 interacting with coastal areas).

554 From these results, we consider that obtaining good climatological and $E T_{o}$

555 estimates over Portugal using observations located in Spain is possible, but these

556 estimates are expected to be of better quality during winter, when synoptic

557 conditions over IP is highly correlated. Unfortunately, $E T_{o}$ estimates are most

558 relevant during the summer months, when AED is high (Fig. 6). During summer

559 local conditions become more important and correlations between Portugal and

560 the rest of the IP become more fragmented.

\section{${ }_{561}$ 5. Discussion}

562 5.1. Meteorological estimates

563 The mean climatic fields presented in Figure 5 describe the climatology of 564 the IP. The northern and northwestern regions are the wettest and coolest, with 565 the lowest values of $E T_{o}, S D$, and $T_{\max }$ and $T_{\min }$, and higher values of $R H$. 566 The highest $T_{\max }$ and $T_{\min }$ are mostly concentrated in the southern half, with 567 the Guadalquivir River valley standing out, with the exception of the Ebro River

568 valley in the northeast, which forms a depression with a characteristic semi-arid 569 local climate. 
Obtained values of $E T_{o}$ are in concordance with previous studies in the Iberian Peninsula, taking into account that other studies were developed using only a subset of weather stations (Vicente-Serrano et al. (2014c) used 46 weather stations in the Spanish part of the IP) or only analyzed a subregion in the IP (such as Vanderlinden et al., 2008 and Espadafor et al., 2011, who analyzed only Andalusia). The same spatial distribution of $E T_{o}$ was detected by some of those previous works. The higher values appear in the southern region and the lower values in the northern region of the IP. The Ebro Valley, a region located in the north, is an exception to this latitudinal pattern, showing high values of $E T_{o}$. The absolute values detected in our study are quite similar to the values of previous studies, with maximum values higher than $1400 \mathrm{~mm}$ in the Guadalquivir Valley, and values lower than $1000 \mathrm{~mm}$ in the northern region. Our results show somewhat higher values in the southern region, up to $1600 \mathrm{~mm}$ at some locations in the Guadalquivir Valley. Some reasons for these higher estimates are: i) We used all the weather stations available; ii) 19612011 period show a clear positive trend in $E T_{o}$, as detected by Espadafor et al. (2011) and Vicente-Serrano et al. (2014a), and our study period (1989-2011) is the last part of that period. Because of that we possibly detected higher mean values than previous studies in some regions. On the other hand, minimum values below $700 \mathrm{~mm}$ in mountainous regions would be in agreement with the detection of low values in Sierra Nevada done by Vanderlinden et al. (2008).

The seasonality of $E T_{o}$ (Fig. 6) follows the well-known seasonal cycles of $T_{\max }, T_{\min }$ and $S D$, with highest $E T_{o}$ in the summer and lowest during the winter months (Espadafor et al., 2011; Vicente-Serrano et al., 2014c; Martins et al., 2017). The higher spatial variability of summer months was also detected in those previous studies.

The correction that meteorological observations impose on the background RCM can be analyzed by the differences between the meteorological fields estimated by the OI and those from the RCM. These differences often present systematic patterns that can be attributed to biases in the RCM, as found by Kotlarski et al. (2014); but they could also be attributed to the impact of cor- 
recting the field with observations that have a footprint smaller than the grid cells. The spatial and temporal variability expected from ground observations is larger because their footprint is representative of a region much smaller than that of the grid cell. For instance, optimally interpolated annual mean values of $T_{\max }$ are higher than those of the RCM, while mean values of $T_{\min }$ are lower, indicating that the RCM tends to dampen thermal oscillations in most of the spatial domain. This correction is spatially consistent, except perhaps in high elevation regions. The only variable that shows very contrasting spatial corrections of different sign is $R H$, since OI tend to increase the lower values of $R H$ in the northern half of the IP and decrease the highest values in the south. This spatial correction pattern of $R H$ is very similar to the differences in the mean $E T_{o}$ field calculated from the OI variables and from the $E T_{o}$ calculated from the uncorrected RCM variables, which reinforces the conclusions by Azorin-Molina et al. (2015) that $R H$ is a key driver of $E T_{o}$ in the IP.

Regarding $S D$, annual mean values in the OI field are generally lower than those estimated by the RCM. Two main factors could help explain differences in $S D:$ i) the WMO defined $S D$ as the time interval in which the solar radiation exceeds $120 \mathrm{Wm}^{-2}$ (WMO, 2003). While $S D$ obtained from the RCM considers this, the observed $S D$ data is more subjective for the period when the Campbell-Stokes (CS) recorder was used. Kerr and Tabony (2004) compared the perfomance of CS and automatic sensors obtaining a good agreement, but with some differences perhaps because the solar radiation at which the CS starts to record ranges from 106 to $285 \mathrm{Wm}^{-2}$ (Painter, 1981); and, ii) the general over-prediction of solar radiation affecting climate models could also be affecting the RCM used in this study (Wild et al., 2013). In fact, our correction of $S D$ values are in concordance with the results obtained for solar radiation by Ruiz-Arias et al. (2015).

Finally, while we expected higher spatial variability of $W$ in the observational dataset than in the RCM, the annual mean values of the OI fields are lower than those of the RCM. Wind speed is a complex variable, with high local spatial variability that physical models find difficult to capture. In fact, some 
authors (e.g. Ishak et al., 2010) detected that dynamically downscaling a global reanalysis did not improve the quality of the $W$ field with respect to the original reanalysis. Moreover, an experiment using the WRF (Skamarock and Klemp, 2008) regional climate model in the north of the IP by Jiménez and Dudhia (2012) showed that wind speeds calculated at grid points were poor predictors of values observed at the closest ground observatories.

In the IP, Martins et al. (2017) tested a blended reanalysis developed by Sheffield et al. (2006), which combined data from distinct sources to obtain a global reanalysis of better quality than any of the individual sources. Usually, the global products have a coarser spatial resolution $\left(0.5^{\circ}\right.$ in this case), than regional products $\left(0.11^{\circ}\right.$ for our product $)$. While they used weather observations to validate the results they obtained, we preferred not to do that because the value of a weather observation refers to an exact point, while the values of OI refer to a grid cell. Nevertheless, as it has been previously explained, both the spatial and temporal distribution of our product are coherent with results obtained by previous studies.

\subsection{Uncertainty of estimates}

Our methodology makes a number of assumptions that are worth discussing before interpreting the results. We consider that the uncertainty of background (RCM) estimates $\mathbf{P}$ equals to their monthly variance. This assumption is based on the idea that monthly estimates of a variable are random variables, and that each year in the RCM record is one sample of the variable for each month. Under this assumption and in the absence of additional information, the historical variability (the sample variance) of the RCM estimates for a given month of the year is the uncertainty around the estimate of this variable. Note that we are not inferring monthly climatologic means, whose uncertainty is represented by the standard error of the mean, but values for each particular month in the record, so the sample variance (the climatological variability) and not the standard error is a more appropriate measure of their uncertainty.

We believe this choice provides a conservative (pessimistic) estimate of the 
background uncertainty because it does not leverage information available from previous months.

An alternative approach to parameterize $\mathbf{P}$ would be to use the variance from an ensemble of models (e.g. from the CORDEX project). We argue that this approach would underestimate the actual uncertainty of the estimates because the limited number of models included in the ensemble, and because the finite conceptualisations of the reality that they implement, sample only a limited range of the actual uncertainty (Knutti, 2010). For this, and for its simplicity, we preferred to provide the initial estimate of uncertainty from the monthly climatology of the RCM. Recently, the ERA5 (new reanalysis of the ECMWF) was made available for the period 2010-2016, and includes a measure of its uncertainty. A comparison between both approaches to parameterize $\mathbf{P}$ will be possible when the full temporal record in the ERA5 dataset becomes available (Hersbach and Dee, 2016)

A second relevant consideration is the prescription of matrix $\mathbf{R}$, which represents the error variance of the observations. We assumed that observational or instrument errors, which are seldom documented, are negligible compared to the station representativity error, which quantifies the uncertainty associated with the local conditions measured by a given station being representative of the cell where the station is located. To approximate this uncertainty we assumed that station errors are independent from each other (i.e., that the matrix $\mathbf{R}$ is diagonal), and that the uncertainty of each station is inversely proportional to the number of data occurring inside a specific grid cell, such that the higher the number of observatories used to estimate the mean value of a grid cell the lower the observational uncertainty for that cell.

Figure 10 shows that variables that are sampled by a large number of stations ( $T_{\min }$ and $T_{\max }$ ), variations in $\mathbf{R}$ affect only the uncertainty while the estimates themselves are not affected. This is because errors in $\mathbf{R}$ are assumed to be unbiased and independent, which along with the large number of available stations and the high spatial covariation imposed by $\mathbf{P}$ allows for a robust estimation of the spatial field. On the other hand, variables with a smaller num- 
ber of observations such as $R H, W$ and $S D$ show that variations in $\mathbf{R}$ affect both the estimate's uncertainty and the estimates themselves. Interestingly, the case of $R H$ and $W$, both of which experienced a large increase in the number of available observations over time, suggests that there is a threshold in the number of observations beyond which the estimates are mostly unaffected by observation uncertainty. This is indicative of a trade-off between the quantity and the quality of observational information, as we will discuss below.

\subsection{Impact of changes in the density of the observational network}

The generation of meteorological grids using standard interpolation methods, such as kriging and other methods based on distance weighting, is very sensitive to variations in the number and location of the weather stations used Moreover, the density and distribution of ground observations necessary to resolve the spatial variability of the climatic field being reconstructed depends on the degree of spatial autocorrelation of the field. This is because the covariance of the process determines the size of the region each observation is representative of (Silverman and Maneta, 2016). This has non-trivial consequences for any climate analysis performed using these grids, because the varying number of stations used for interpolation may induce trends in the spatial variability (granularity) of the meteorological fields that can easily be misinterpreted as being genuinely caused by a climatic process.

Our analysis (Fig. 8) showed that the spatial standard deviation of the fields produced by OI was not as acutely affected by this problem as traditional interpolation methods are, as demonstrated in previous studies (Beguería et al., 2016). While the rapid increase in the number of observations affected the estimates of $R H, W$ and $S D$ (Fig. 2), the spatial variance of these fields did not show appreciable changes that could be attributed to the densification of the observational network. For $R H$ and $W$, which more than doubled the available data in the last 5 years of the study period, an increase of the granularity of the field could be expected, due to more local effects being detected within the observational network. On the other hand, $S D$ experienced a steady decrease in 
the number of grid cells with data with potential impacts on the granularity of the field. However, we did not find significant temporal trends in the dispersion statistics of the resulting climatic fields. A reason for this is that in the OI scheme, the information about the spatial variability of the climatic field being reconstructed does not exclusively depend on ground observations, as other methods do, but also on the RCM variance-covariance matrix $(\mathbf{P})$, which embeds a physically-based estimation of the spatial variability of the climatic process over the entire domain, including areas sparsely monitored. Since $\mathbf{R}$ is a diagonal matrix, the spatial correction performed by OI mostly depends on $\mathbf{P}$ (i.e. on the spatial variability of the climate process extracted from the RCM), which is available for all grid points and reduces the dependency of the resulting field variance on ground observations.

On the other hand, the uncertainty of the estimates $\left\langle\boldsymbol{\sigma}^{\boldsymbol{a}}\right\rangle$, represented on Fig. 9, was very sensitive to the number of stations used, especially for $R H$ and $W$. The sharp increment in the density of the observational network for these variables had a strong impact in reducing $\left\langle\boldsymbol{\sigma}_{\boldsymbol{R} \boldsymbol{H}}^{\mathbf{a}}\right\rangle$ and $\left\langle\boldsymbol{\sigma}_{\boldsymbol{W}}^{\mathbf{a}}\right\rangle$. From an algebraic point of view, the increase in the number of grid cells containing data affects the calculation of the gain matrix $\mathbf{K}$ (eq. 2). As $\mathbf{R}$ decreases, $\mathbf{P}$ becomes a larger share of the total error variance represented by $\mathbf{K}$, informing the updates to increase the amount of correction on the prior estimates (i.e. observations gain influence). When the variance update formula is used to calculate the posterior uncertainty of the estimate $\left(\mathbf{P}^{+}\right), \mathbf{K}$ induces a larger reduction in the background uncertainty $(\mathbf{P})$.

Similarly, a decrease in the number of observations, such as in the case of $S D$, results in an increase in $\left\langle\boldsymbol{\sigma}_{S D}^{\mathbf{a}}\right\rangle$. This also happens, albeit to a smaller extent, with $T_{\max }$ and $T_{\min }$. Nevertheless, the increment in the number of $R H$ and $W$ observations was more important than the decrease in the number of observations in these three variables, and the overall uncertainty in the $E T_{o}$ estimate, $\left\langle\boldsymbol{\sigma}_{\boldsymbol{E} \boldsymbol{T}_{o}}^{\mathbf{a}}\right\rangle$, decreased over the study period. 


\section{Conclusions}

1. The use of an OI scheme blending background RCM data with observational data from a relatively dense network allowed estimating fields of the variables needed to compute fields of FAO-PM $E T_{o}$.

2. OI also allowed propagating the initial uncertainty of the data to the OI estimated fields, which were then propagated through the Jacobian of FAO-PM equation to finally get $E T_{o}$ uncertainty fields.

3. The granularity of the estimated $E T_{o}$ fields, as measured through their spatial variance, was not affected by changes in the number of stations in the observational network, which were noticeable during the study period. This can be attributed to the physically-coherent information on the spatial structure of the variables provided by the RCM, and contrasts with other methods that rely on observational data alone.

4. The uncertainty of the meteorological variables and therefore of $E T_{o}$ was, however, sensitive to changes in the number of stations used. In this sense, we found that in our case study the number and spatial distribution of temperature records was adequate for the spatial resolution of our analysis, while a recent increase in the number of air humidity and wind speed stations substantially reduced the uncertainty of computed $E T_{o}$. A reduction was found in the number of sunshine duration stations that affected negatively the computation of $E T_{o}$.

5. The propagation of uncertainty is a highly relevant issue when constructing meteorological grids but it is often neglected, probably due to difficulties in determining the uncertainty of the original data sources. In this case a number of assumptions were made to quantify the uncertainties of the RCM and observational data used and their consequences were checked and discussed, but other options could be explored. 


\section{Acknowledgments}

This work has been supported by the research project CGL2014-52135-C3-1R, financed by the Spanish Ministerio de Economía, Industria y Competitividad (MINECO) and EU-FEDER. M Maneta acknowledges support from the National Science Foundation EPSCoR Cooperative Agreement EPS-1101342, NSF Contracts GSE-1461576 and DGE-1633831, and USDA NIFA contract 201667026-25067. The work of M. Tomas-Burguera was supported by the predoctoral FPU program 2013 (Ministerio de Educación, Cultura y Deporte). We wish to thank the Spanish national meteorological service (AEMET) for providing the observational data necessary to carry out this study. We acknowledge the World Climate Research Programme's Working Group on Regional Climate, and the Working Group on Coupled Modelling, former coordinating body of CORDEX and responsible panel for CMIP5. We also thank the DMI climate modelling group for producing and making available HIRHAM model output. We also acknowledge the Earth System Grid Federation infrastructure an international effort led by the U.S. Department of Energy's Program for Climate Model Diagnosis and Intercomparison, the European Network for Earth System Modelling and other partners in the Global Organisation for Earth System Science Portals (GO-ESSP)." We declare that we have no competing interests.

\section{References}

Abatzoglou, J.T. (2013). Development of gridded surface meteorological data for ecological applications and modelling. Int. J. Climatol. 33:121-131. doi:10.1002/joc.3413

Allen, R.G., Pereira, L.S., Raes, D.,Smith, M. (1998). Crop evapotranspiration - guidelines for computing crop water requirements. FAO Irrigation and Drainage Paper 56, FAO, Rome Italy

Azorin-Molina, C., Vicente-Serrano, S.M., Sanchez-Lorenzo,A., McVicar, T.R., Morán-Tejeda, E., Revuelto, J., El Kenawy, A., Martín-Hernández, N., 
Tomas-Burguera, M. (2015). Atmospheric evaporative demand observations, estimates and driving factors in Spain (1961-2011). J. Hydrol. 523, 262-277. doi:10.1016/j.jhydrol.2015.01.046

Azorin-Molina, C., Guijarro, J.A., McVicar, T.R., Vicente-Serrano, S.M., Chen, D., Jerez, S., Espírito-Santo, F. (2016). Trends of daily peak wind gusts in Spain and Portugal, 1961-2014. J. Geophys. Res. Atmos. 121, 1059-1078.

Blaney, H.F., Criddle, W.P. (1950). Determining water requirements in irrigated areas from climatological and irrigation data. USDA (SCS) TP-96, 48

Brohan, P., Kennedy, J.J., Harris, I., Tett, S.F.B., Jones, P.D. (2006). Uncertainty estimates in regional and global observed temperature changes: A new data set from 1850. J. Geophys. Res. Atmos. 111, D12106, doi:10.1029/2005JD006548.

Beguería, S., Vicente-Serrano, S.M., Tomas-Burguera, M., Maneta, M. (2016). Bias in the variance of gridded data sets leads to misleading conclusions about changes in climate variability. Int. J. Climatol. 36, 3413-3422.

Christensen, O.B., Drews, M., Christensen, J.H., Dethloff, K., Ketelsen, K., Hebestadt, I., Rinke, A. (2006). The HIRHAM regional climate model. Version 5. DMI Technical Report 06-17. Available from DMI

Dee, D.P., Uppala, S.M., Simmons, A.J., Berrisford, P., Poli, P., Kobayashi, S., Andrae, U., Balmaseda, M.A., Balsamo, G., Bauer, P., Bechtold, P., Beljaars, A.C.M., van de Berg, L., Bidlot, J., Bormann, N., Delsol, C., Dragani, R., Fuentes, M., Geer, A.J., Haimberger, L., Healy, S.B., Hersbach, H., Hólm, E.V., Isaksen, L., Kallberg, P., Köhler, M., Matricardi, M., McNally, A.P., Monge-Sanz, B.M., Morcrette, J.-J., Park, B.-K., Peubey, C., Rosnay, P. de, Tavolato, C., Thépaut, J.-N., Vitart, F. (2011). The ERA-Interim reanalysis: configuration and performance of the data assimilation system. Q.J.R. Meteorol. Soc. 137, 553-597 
Espadafor, M., Lorite, I.J., Gavilán, P., Berengena, J. (2011). An analysis of the tendency of reference evapotranspiration estimates and other climate variables during the last 45 years in Southern Spain. Agricultural Water Management 98, 1045-1061.

Giorgi, F., Jones, C., Ghassem, R. (2009). Addressing climate information needs at the regional level: the CORDEX framework. World Meteorol. Organizat. Bull. 58 (3), 175-183.

Hargreaves, G.H., Samani, Z.A. (1985). Reference crop evapotranspiration from temperature. Appl. Eng. Agric 1, 96-99.

Harris, I., Jones, P., Osborn, T., Lister, D. (2014). Updated high-resolution grids of monthly climatic observations - The CRU TS 3.10 dataset. Int. J. Climatol. 34 (3), 623-642.

Hart, Q.J., Brugnach, M., Temesgen, B., Rueda, C., Ustin, S.L., Frame, K. (2009). Daily reference evapotranspiration for California using satellite imagery and weather station measurement interpolation. Civil Engineering and Environmental Systems 26 (1), 19-33.

Haslinger, K., Bartsch, A. (2016). Creating long-term gridded fields of reference evapotranspiration in Alpine terrain based on a recalibrated Hargreaves method. Hydrol. Earth Syst. Sci. 20, 1211-1223.

Hersbach, H., Dee, D. (2016). ERA5 reanalysis is in production. ECMWF Newsletter 147,7 .

Hosseinzadehtalaei, P., Tabari, H., Willems, P. (2016). Quantification of uncertainty in reference evapotranspiration climate change signals in Belgium. Hydrology Research 26 (1), 19-33.

Kay, A.L., Davies, H.N. (2008). Calculating potential evaporation from climate model data: A source of uncertainty for hydrological climate change inputs. J. Hydrol. 358, 221-239 
Kerr, A., Tabony, R. (2004). Comparison of sunshine recorded by CampbellStokes and automatic sensors. Weather 59 (4), 90-95

Irmak, S., Kabenge, I., Skaggs Mutiibwa, K.E.D. (2012). Trend and magnitude of changes in climate variables and reference evapotranspiration over 116-yr period in the Platter river basin, Central Nebraska-USA. J. Hydrol. 420-421, 228-244.

Ishak, A.M., Bray, M., Remesan, R., Han, D. (2010). Estimating reference evapotranspiration using numerical weather modelling. Hydrol. Process. 24, 34903509

Jiménez, P.A., Dudhia, J. (2012). Improving the representation of resolved and unresolved topographic effects on surface wind in the WRF model $J$. Appl. Meteor. Climatol. 51, 300-316

Kalnay, E., Kanamitsu, E., Kistler, R., Collins, W., Deaven, D., Gandin, L., Iredell, M., Saha, S., White, G., Woollen, J., Zhu, Y., Chelliah, M., Ebisuzaki, W., Higgins, W., Janowiak, J., Mo, K.C., Ropelewski, C., Wang, J., Leetmaa, A., Reynolds, R., Jenne, R., Joseph, D. (1996). The NCEP/NCAR 40-year reanalysis project. Bull. Amer. Meteor. Soc. 77, 437-471

Kendall, M.G. (1975). Rank Correlation Methods Griffin, London

Kingston, D.G., Todd, M.C., Taylor, R.G., Thompson, J.R., Arnell, N.W. (2009). Uncertainty in the estimation of potential evapotranspiration under climate change Geophys. Res. Lett. 36, L20403 doi:10.1029/2009GL040267

Knutti, R. (2010). The end of model democracy? An editorial comment. Climatic Change 102, 395-404

Kotlarski, S., Keuler, K., Christensen, O.B., Colette, A., Déqué, M., Gobiet, A., Goergen, K., Jacob, D., Lüthi, D., van Meijgaard, E., Nikulin, G., Schär, C., Teichmann, C., Vautard, R., Warrach-Sagi, K. and Wulfmeyer, V. (2014). Regional climate modeling on European scales: a joint standard evaluation of the EURO-CORDEX RCM ensemble Geosci. Model Dev. 7, 1297-1333 
Lewis, C.S., Allen, N.L. (2016). Potential Crop Evapotranspiration and Surface Evaporation estimates via a gridded weather forcing dataset. J. Hydrol. 546, 450-463. doi:10.106/j.jhydrol.2016.11.055

Lusana, C. (2017). Spatial Interpolation of daily minimum, maximum and mean temperature Norwegian Meteorological Institute Technical Report. 02/2017. ISSN: $2387-4201$

Man, H.B. (1945). Nonparametric tests against trend. Econometrica 13, 245-259 Mardikis, M.G., Kalivas, D.P., Kollias, V.J. (2005). Comparison of interpolation methods for the prediction of reference evapotranspiration - an application in Greece. Water Resour. Manag. 19 (3), 251-278

Martins, D.S., Paredes, P., Raziei, T., Pires, C., Cadima, J., Pereira, L.S. (2017). Assessing reference evapotranspiration estimation from reanalysis weather products. An application to the Iberian Peninsula. Int. J. Clim. 37 (5), 23782397

McVicar, T.R., Van Niel, T.G., Li, L., Hutchinson, M.F., Mu, X., Liu, Z. (2007). Spatially distributing monthly reference evapotranspiration and pan evaporation considering topographic influences. J. Hydrol. 338, 196-220.

McVicar, T.R., Roderick, M.L., Donohue, R.J., Van Niel, T.G. (2012). Less bluster ahead?Echohydrological implication of globals trends of terrestrial near-surface wind speeds. Ecohydrology 5 (4), 381-388.

Morice C.P., Kennedy, J.J., Rayner, N.A., Jones, P.D. (2012). Quantifying uncertainties in global and regional temperature change using an ensemble of observational estimates: The HadCRUT4 data set J. Geophys. Res. 117, D08101, doi:10.1029/2011JD017187.

Painter, H.E. (1981). The performance of a Campbell-Stokes sunshine recorder compared with a simultaneous record of the normal incidence irradiance $\mathrm{Me}$ teorol. Mag. 110, 102-109. 
Priestley, C.H.B., Taylor, R.J. (1972). On the assessment of the surface heat flux and evaporation using large-scale parameters Mon. Weather Rev. 100, 81-92.

Prudhomme, C., Williamson, J. (2013). Derivation of RCM-driven potential evapotranspiration for hydrological climate change impact analysis in Great Britain: a comparison of methods and associated uncertainty in future projections Hydrol. Earth Syst. Sci. 17, 1365-1377.

Reynolds, R.W., Rayner, N.A., Smith, T.M., Stokes, D.C., Wang, W. (2002). An improved in situ and satellite SST analysis for climate J. Climate 15, $1609-1625$

Riosalido, R., Vázquez, L., Gordo, A., Jansà, A. (1986). Cierzo: Northwesterly wind along the Ebro Valley as a meso-scale effect induce don the lee of the Pyrenees mountain range: a case study during ALPEX Special Period. Scientific Results of the Alpine Experiment (ALPEX), Vol. 2. WMO/TD 108, $565-575$.

Robinson, E.L., Blyth, E.M., Clark, D.B., FInch, J., Rudd, A. (2017). Trends in atmospheric evaporative demand in Great Britain using high-resolution meteorological data Hydrol. Earth Syst. Sci. 21 , 1189-1224.

Ruiz-Arias, J.A., Quesada-Ruiz, S., Fernandez, E.F., Gueymard, C.A. (2015). Optimal combination of gridded and ground-observed solar radiation data for regional solar resource assessment Solar Energy 112, 411-424.

Sanchez-Lorenzo, A., Calbó, J., Wild, M. (2013). Global and diffuse solar radiation in Spain: Building a homogeneous dataset and assessing their trends Global and Planetary Change 100 , 343-352. doi:10.1016/j.gloplacha.2012.11.010

Silverman, N.L., Maneta, M.P.. (2016). Detectability of change in winter precipitation within mountain landscapes: Spatial patterns and uncertainty. Water Resour. Res. 52 , 4301-4320. doi:10.1002/2014WR016493 
${ }_{944}$ Skamarock, W.C., Klemp, J.B. (2008). A time-split nonhydrostatic atmospheric

${ }_{945}$ model for weather research and forecasting applications. J. Comput. Phys. 227 (7) ,3465-3485. doi:10.1016/j.jcp.2007.01.037

947 Strong, C., Khatri, K.B., Kochanski, A.K., Lewis, C.S., Niel Allen, L. (2017).

${ }_{948}$ Reference evapotranspiration from coarse-scale and dynamically downscaled 949 data in complex terrain: Sensitivity to interpolation and resolution. J. Hydrol. 950 $\quad 548,406-418$. doi:10.1016/j.jhydrol.2017.02.045

951 Tomas-Burguera, M., Vicente-Serrano, S.M., Beguería, S. (2017). Accuracy of reference evapotranspiration (ETo) estimates under data scarcity scenarios in the Iberian Peninsula. Agricultural Water Management 182 (1), 103-116.

Uppala, S.M., Kållberg, P.W., Simmons, A.J., Andrae, U., Bechtold, V.D.C., Fiorino, M., Gibson, J.K., Haseler, J., Hernandez, A., Kelly, G.A., Li, X., Onogi, K., Saarinen, S., Sokka, N., Allan, R.P., Andersson, E., Arpe, K., Balmaseda, M.A., Beljaars, A.C.M., Berg, L.V.D., Bidlot, J., Bormann, N., Caires, S., Chevallier, F., Dethof, A., Dragosavac, M., Fisher, M., Fuentes, M., Hagemann, S., Hölm, E., Hoskins, B.J., Isaksen, L., Janssen, P.A.E.M., Jenne, R., Mcnally, A.P., Mahfouf, J.F., Morcrette, J.J., Rayner, N.A., Saunders, R.W., Simon, P., Sterl, A., Trenberth, K.E., Untch, A., Vasiljevic, D., Viterbo, P., Woollen, J. (2005). The ERA-40 reanalysis. Quarterly Journal of the Royal Meteorogical Society 131, 2961-3012. doi:10.1256/qj.04.176

Vanderlinden, K., Vicente Giráldez, J., Van Mirvenne, M. (2008). Spatial Estimation of Reference Evapotranspiration in Andalusia, Spain. Journal of Hydrometeorology 9 (2), 242-255, doi:10.1175/2007JHM880.1

Vicente-Serrano, S.M., Azorin-Molina, C., Sanchez-Lorenzo, A., Revuelto, J., López-Moreno, J.I., González-Hidalgo, J.C., Moran-Tejeda, E., Espejo, F. (2014). Reference evapotranspiration variability and trends in Spain, 19612011 Global and Planetary Change 121, 26-40

Vicente-Serrano, S.M., Azorin-Molina, C., Sanchez-Lorenzo, A., Morán-Tejeda, E., Lorenzo-Lacruz, J., Revuelto, J., López-Moreno, J.I., Espejo, F. (2014). 
973 Temporal evolution of surface humidity in Spain: recent trends and possible

$974 \quad$ physical mechanisms. Clim Dyn 42 (9), 2655-2674

975 Vicente-Serrano, S.M., Azorin-Molina, C., Sanchez-Lorenzo, A., Revuelto, J., 976 Morán-Tejeda, E, López-Moreno, J.I., Espejo, F. (2014). Sensitivity of ref977 erence evapotranspiration to changes in meteorological parameters in Spain 978 (1961-2011). Water Resour. Res. 50, 8458-8480, doi:10.1002/2014WR015427

${ }_{979}$ Wild, M., Folini, D., Schär, C., Loeb, N., Dutton, E.G., König-Langlo, G. 98о (2013). The global energy balance from a surface perspective. Clim Dyn 40 $981 \quad(11), 3107-3134$

982 Wikle, C.K., Berliner, L.M. (2007). A Bayesian tutorial for data assimilation ${ }_{983} \quad$ Physica D $230(1), 1-16$

${ }_{984}$ World Meteorological Organization (1989). Calculation of monthly and annual 985 30-year standard normals WMO-NO. 341, Washington D.C.

986 World Meteorological Organization (2003). Manual on the Global Observing 987 System. WMO-NO. 544, Geneva 


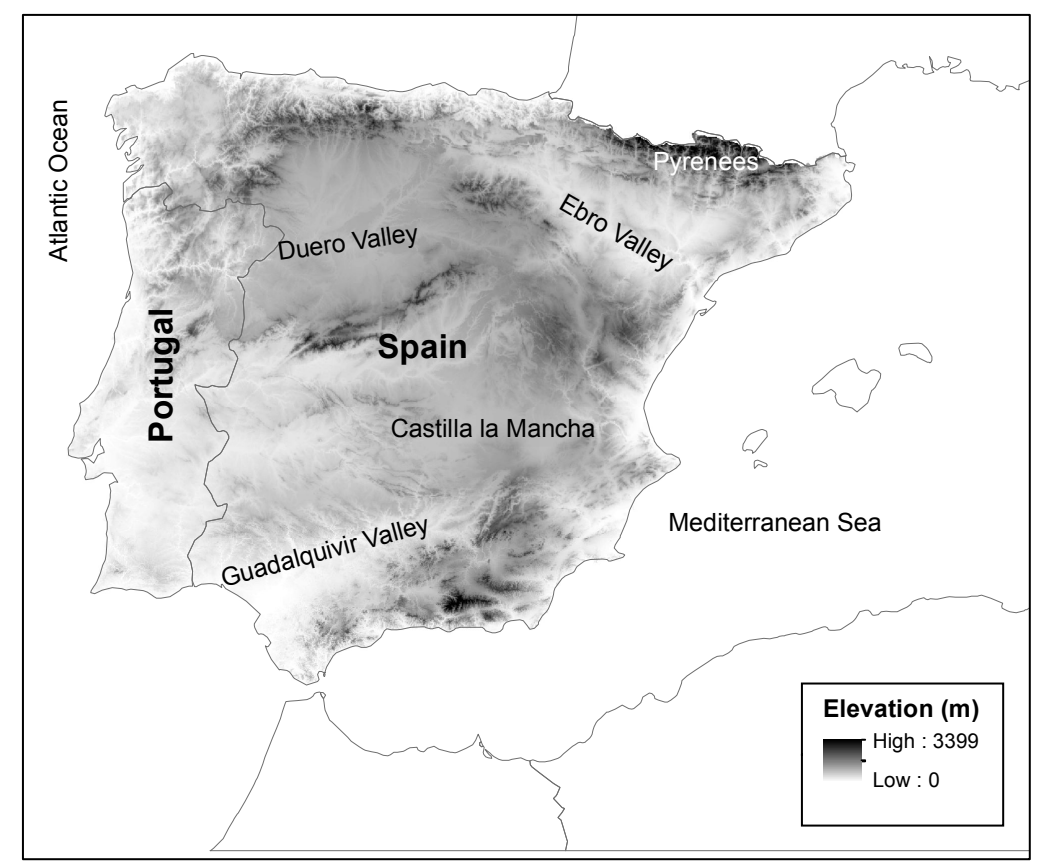

Figure 1: Study area. 
T
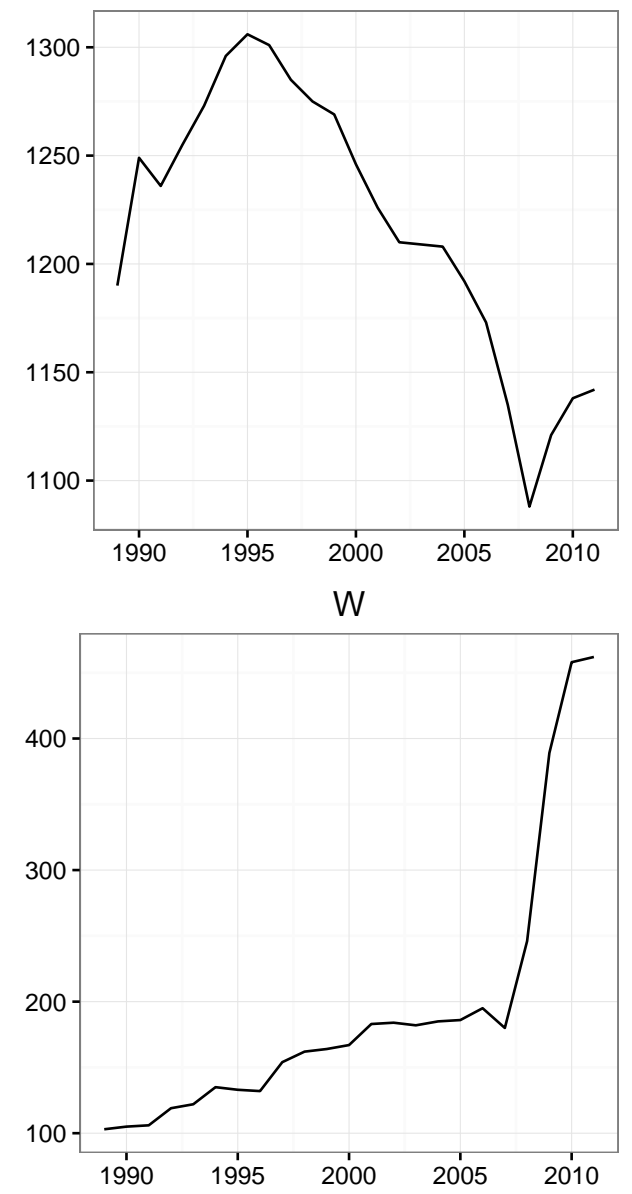

$\mathrm{RH}$
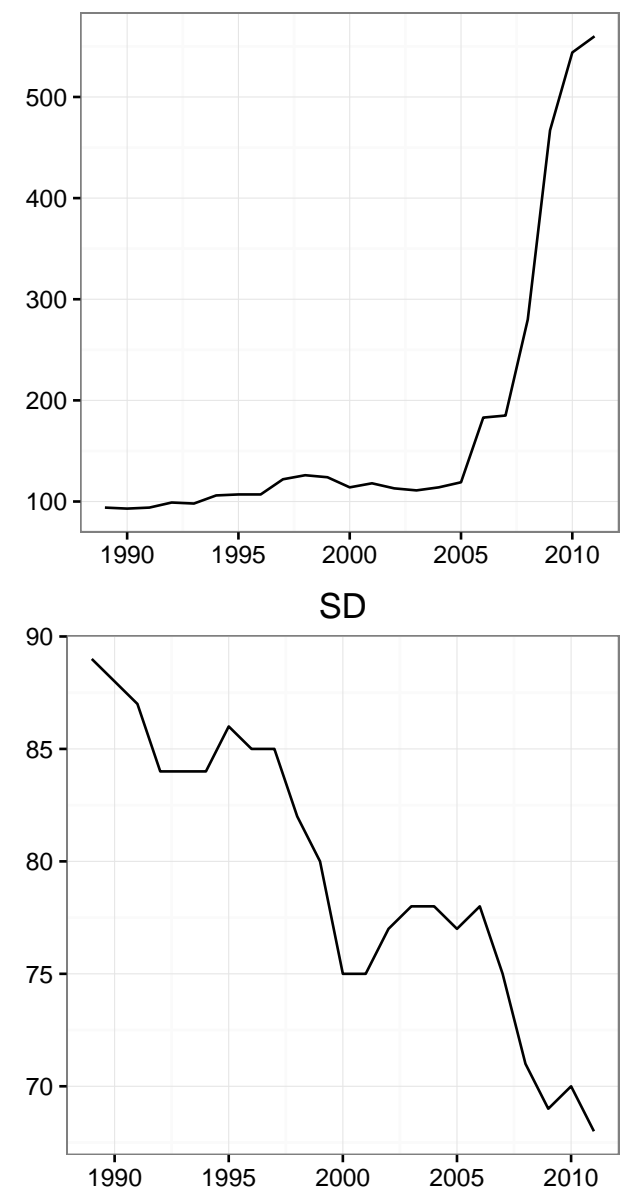

Figure 2: Time series of the number of grid cells containing at least one weather station $(n)$ for temperature, $T$; relative humidity, $R H$; wind speed, $W$; and sunshine duration, $S D$. 


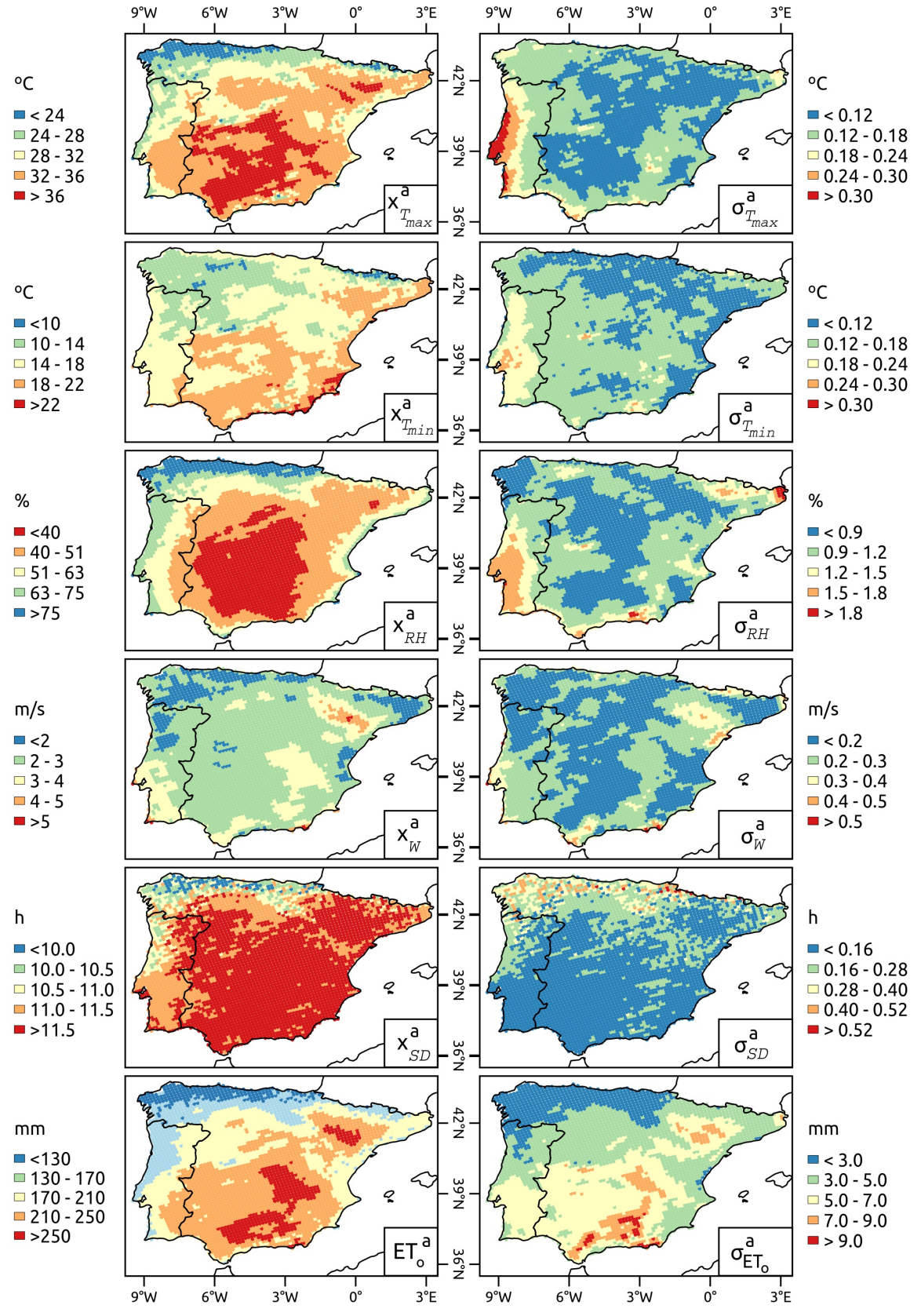

Figure 3: OI estimated mean values $\left(\mathbf{x}_{v}^{\mathbf{a}}\right)$ and standard deviation $\left(\boldsymbol{\sigma}_{v}^{\mathbf{a}}\right)$ of maximum temperature $\left(T_{\max }\right)$; minimum temperature $\left(T_{\min }\right)$; relative humidity $(R H)$; wind speed $(W)$; sunshine duration $(S D)$ and reference evapotranspiration $\left(\mathbf{E} \mathbf{T}_{\mathbf{o}}^{\mathbf{a}}\right.$ and $\left.\boldsymbol{\sigma}_{E T_{o}}^{\mathbf{a}}\right)$, for the month of July 1994 

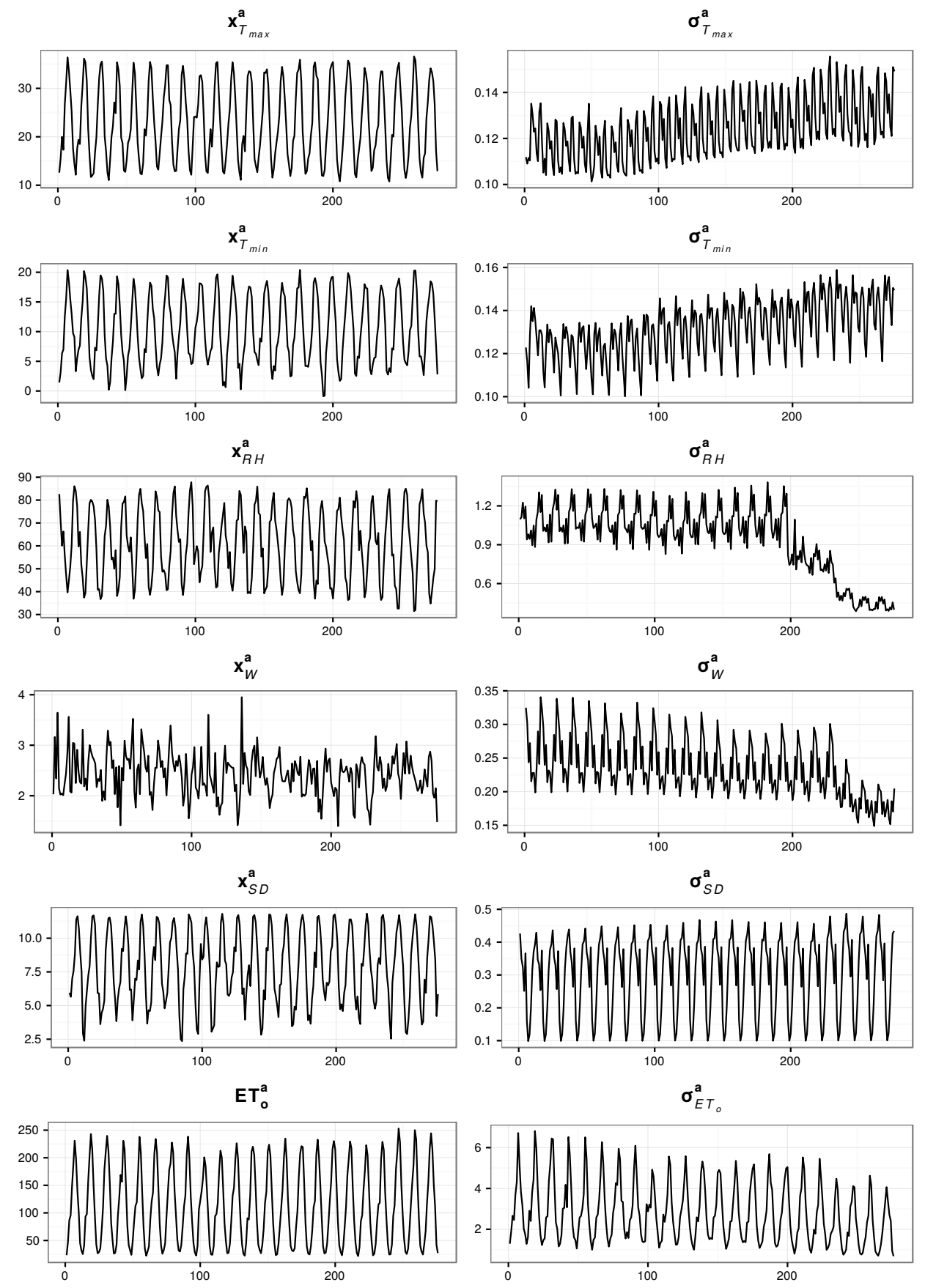

Figure 4: Time series of OI estimated mean values $\left(\mathbf{x}_{v}^{\mathbf{a}}\right)$ and standard deviation $\left(\boldsymbol{\sigma}_{v}^{\mathbf{a}}\right)$ of maximum temperature $\left(T_{\max }\right)$; minimum temperature $\left(T_{\min }\right)$; relative humidity $(R H)$; wind speed $(W)$; sunshine duration $(S D)$ and reference evapotranspiration $\left(\mathbf{E T}_{\mathbf{o}}^{\mathbf{a}}\right.$ and $\left.\boldsymbol{\sigma}_{E T_{o}}^{\mathbf{a}}\right)$, at one random grid cell 


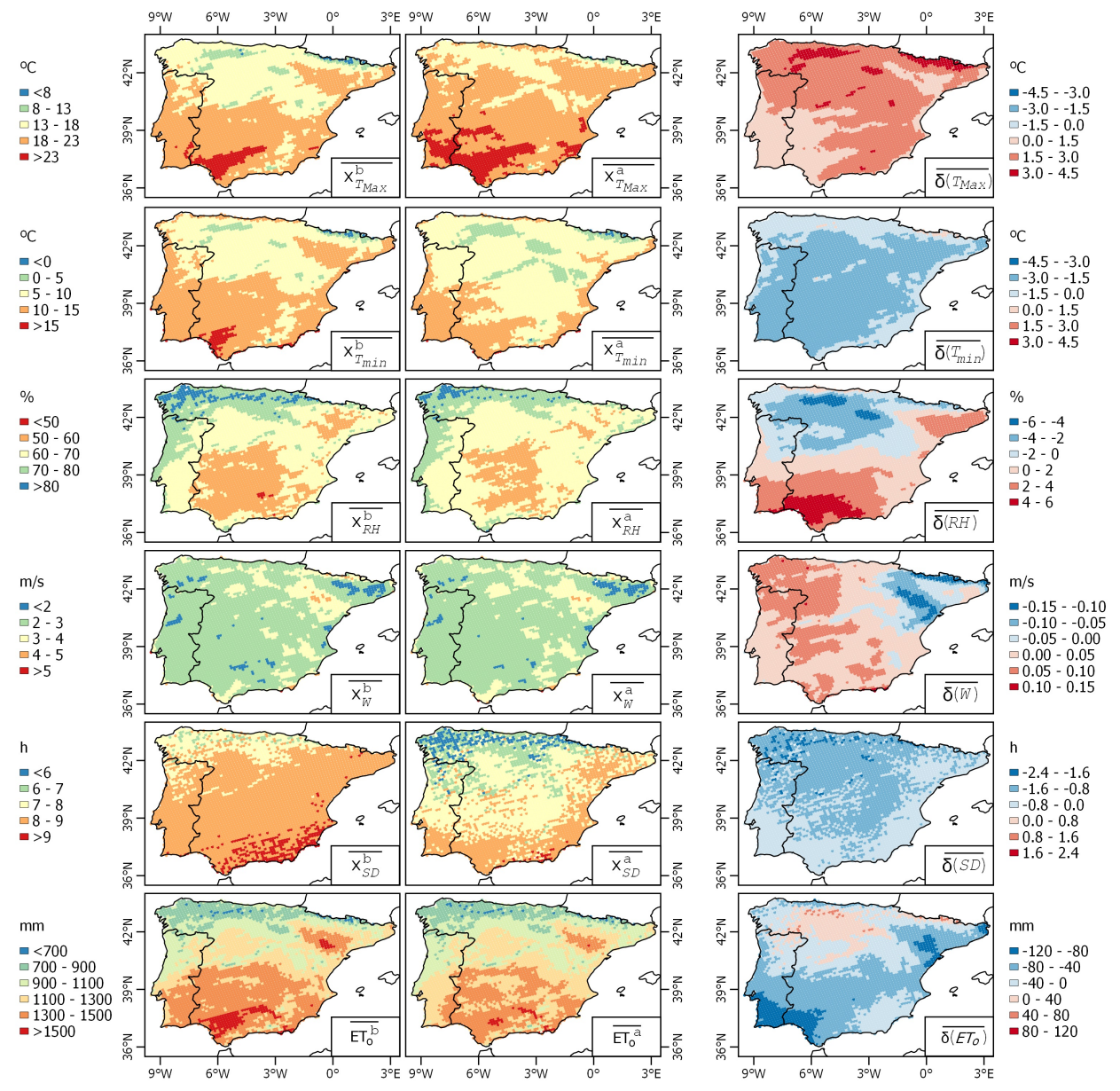

Figure 5: Mean annual values of OI estimated and background RCM $\left(\overline{\mathbf{x}_{v}^{\mathbf{a}}}\right.$ and $\overline{\mathbf{x}_{v}^{\mathbf{b}}}$, respectively $)$ of maximum temperature $\left(T_{\max }\right)$; minimum temperature $\left(T_{\min }\right)$; relative humidity $(R H)$; wind speed $(W)$; sunshine duration, $(S D)$; and reference crop evapotranspiration $\left(\overline{\mathbf{E T}_{\mathbf{o}}^{\mathbf{a}}}\right.$ and $\left.\overline{\mathbf{E T}_{\mathbf{o}}^{\mathbf{b}}}\right)$, and the differences between them $(\overline{\boldsymbol{\delta}})$. 


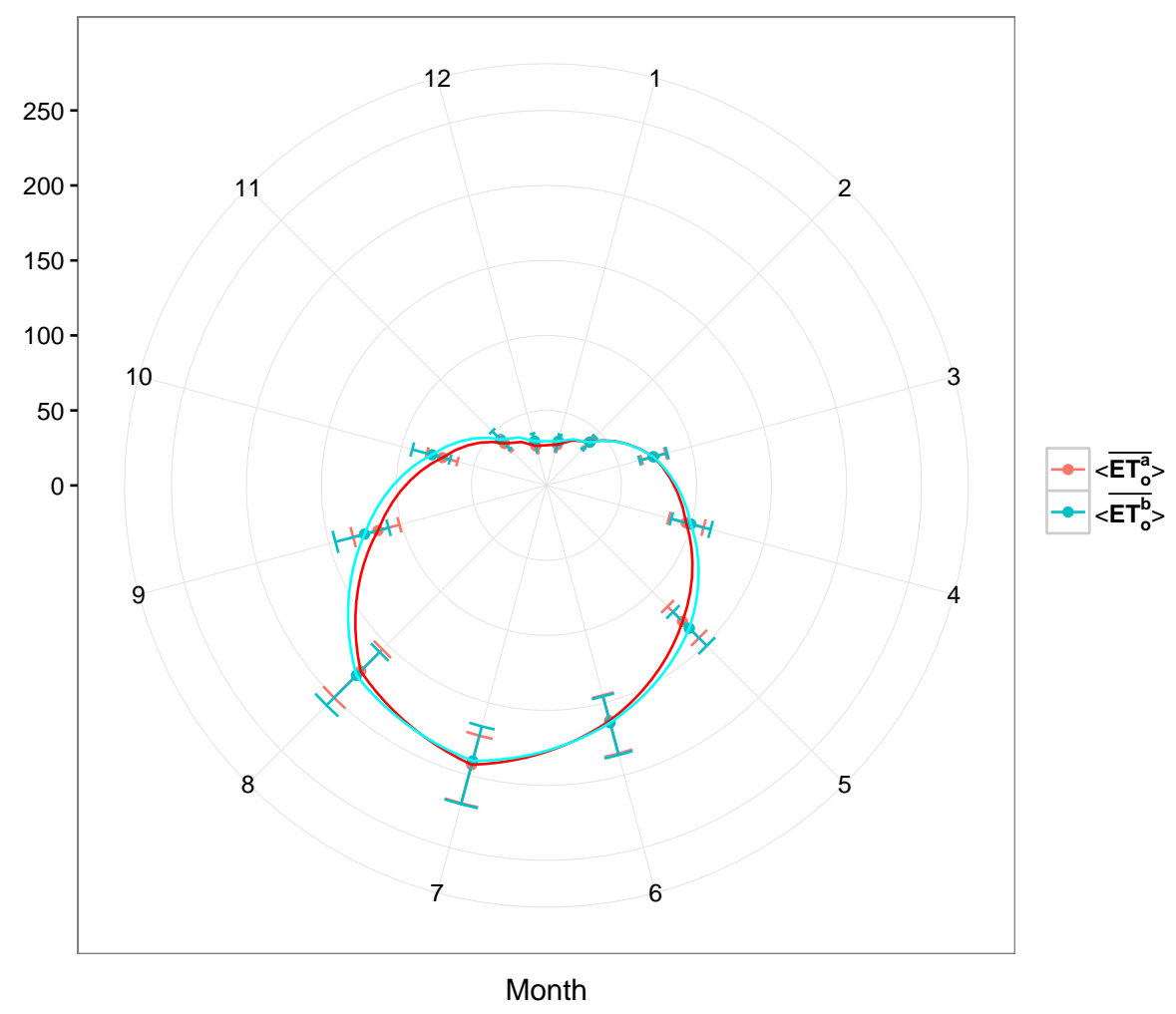

Figure 6: Monthly spatial mean values of OI estimated and background RCM reference crop evapotranspiration $\left(\left\langle\overline{\mathbf{E} \mathbf{T}_{\mathbf{o}}^{\mathbf{a}}}\right\rangle\right.$ and $\left\langle\overline{\mathbf{E} \mathbf{T}_{\mathbf{o}}^{\mathbf{b}}}\right\rangle$, respectively). The error bars indicate the spatial interquartile range. 


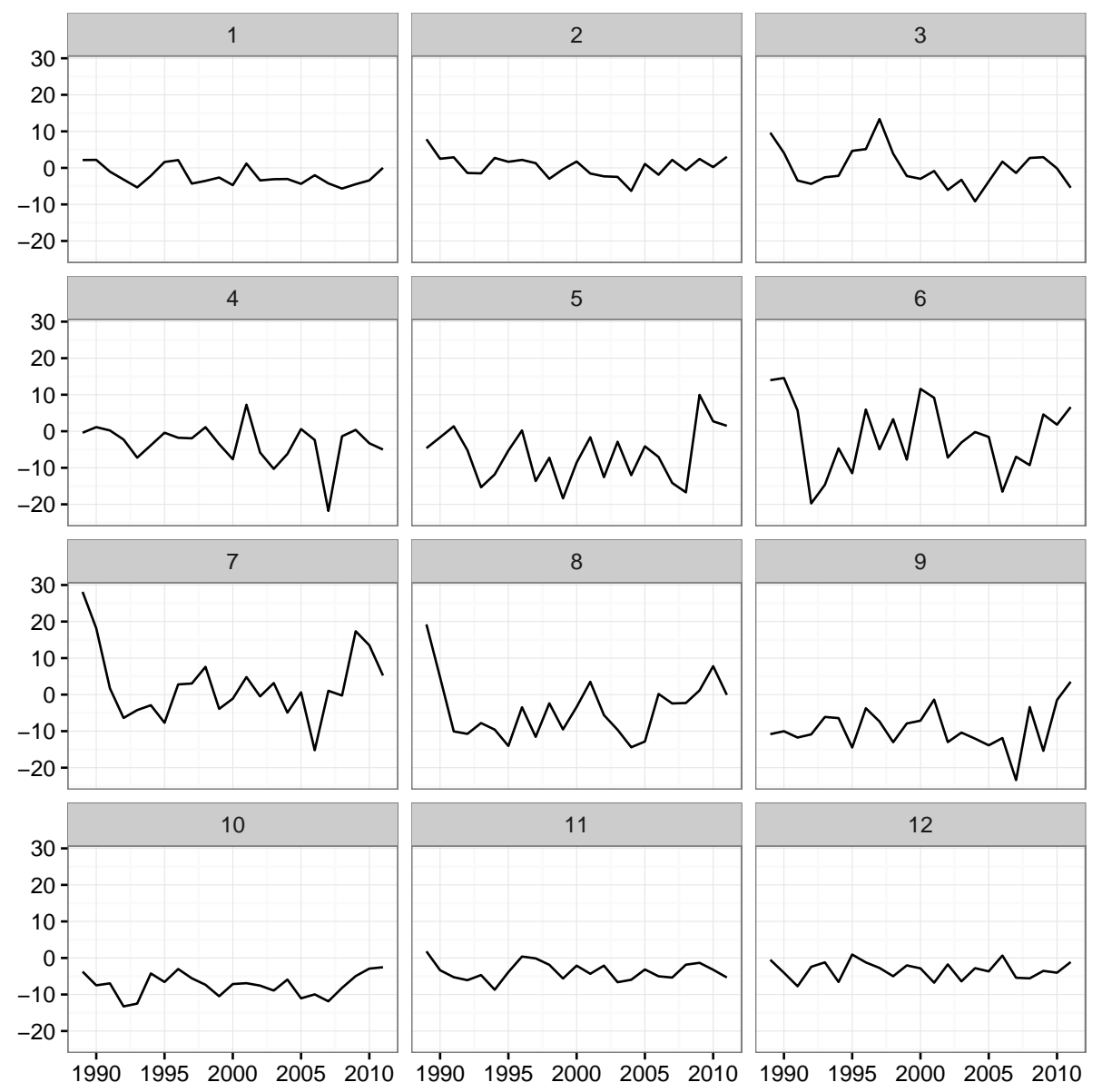

Figure 7: Time series of the spatial mean correction applied to the RCM, $\left\langle\boldsymbol{\delta}_{E T_{o}}\right\rangle=\left\langle\mathbf{E T}_{\mathbf{o}}^{\mathbf{a}}-\right.$ $\mathbf{E T}_{\mathbf{o}}^{\mathbf{b}}>$, for each month (1 indicating January, etc). 


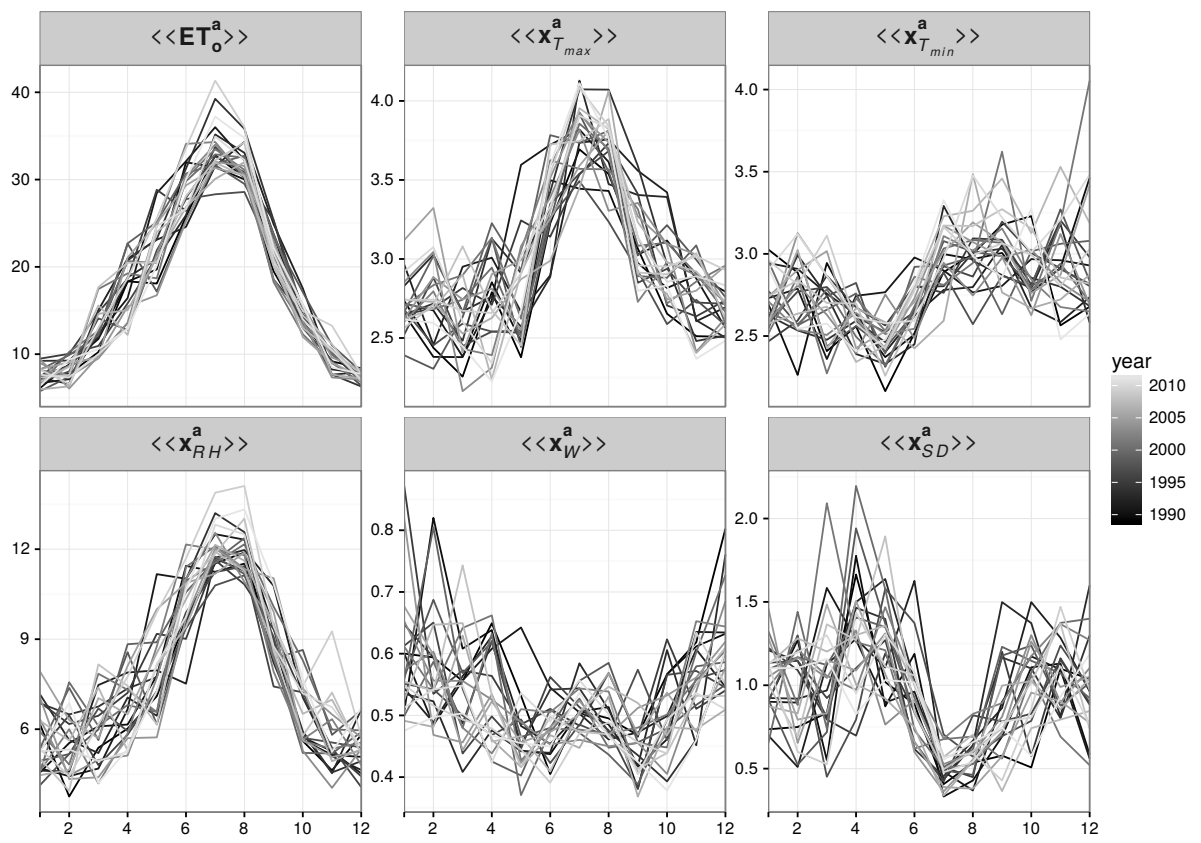

Figure 8: Time series of the spatial standard deviation of input variables ( $\left.« \mathbf{x}_{v}^{\mathbf{a}_{v}}\right)$ and $\left(\left\langle\mathbf{E} \mathbf{T}_{\mathbf{o}}^{\mathbf{a}} »\right)\right.$. Different shades of gray indicate years, and the months are in the x-axis (1 indicating January, etc). 


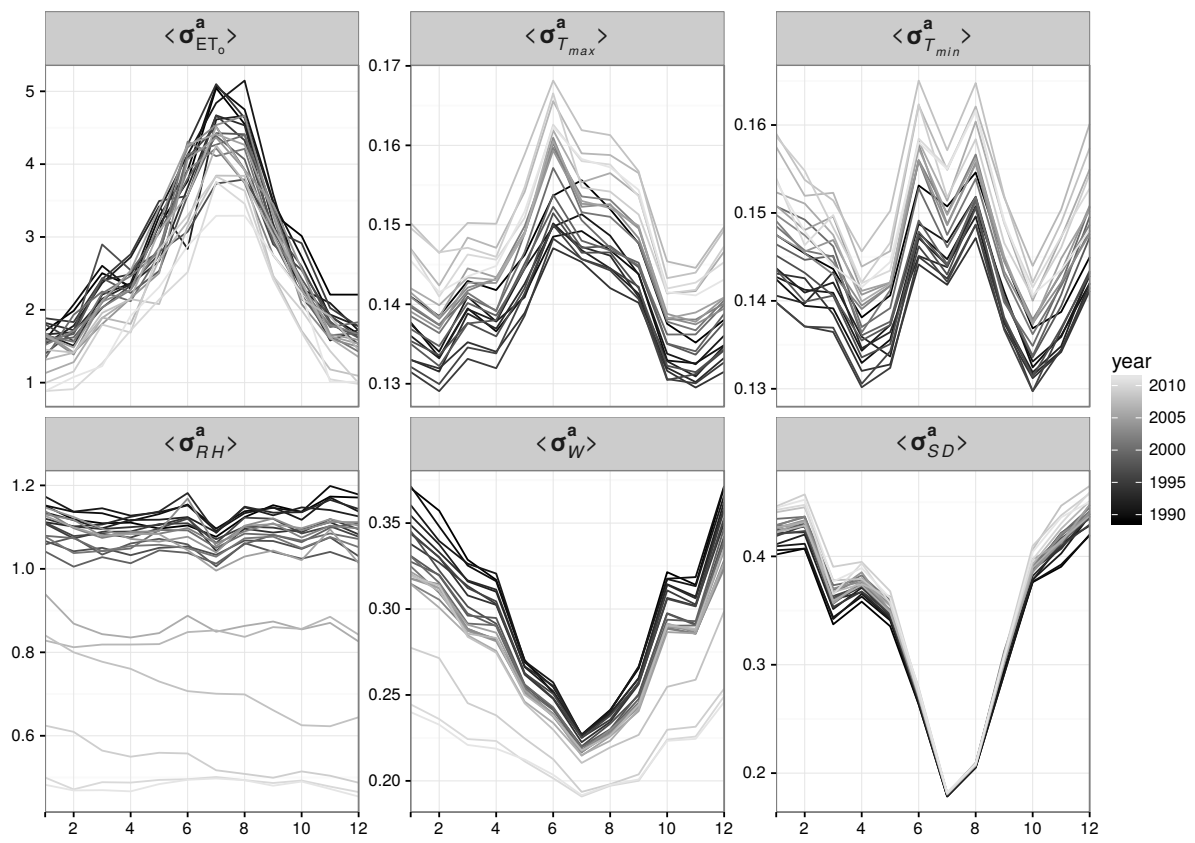

Figure 9: Time series of the spatial mean of the uncertainty of climate variables, $\left\langle\boldsymbol{\sigma}^{\mathbf{a}}\right\rangle$, and $E T_{o},\left\langle\boldsymbol{\sigma}_{E T_{o}}^{\mathbf{a}}\right\rangle$. Different shades of gray indicate years, and the months are in the x-axis (1 indicating January, etc). 


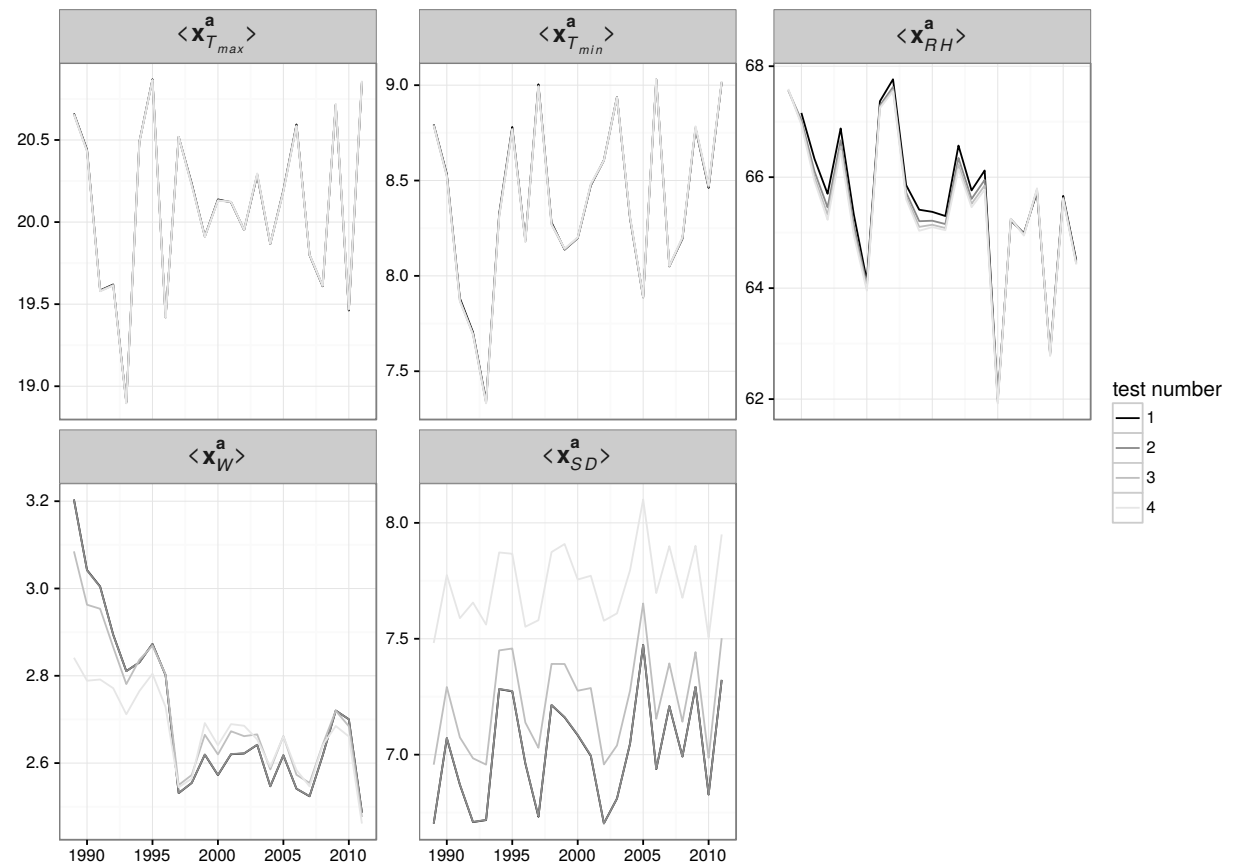

Figure 10: Time series of spatial mean values of each climatic variable $\left(\left\langle\mathbf{x}_{v}^{\mathbf{a}}\right\rangle\right)$, as a function of different values of $\beta$. The exact values of $\beta$ for each variable and test number are given in Table 2. 


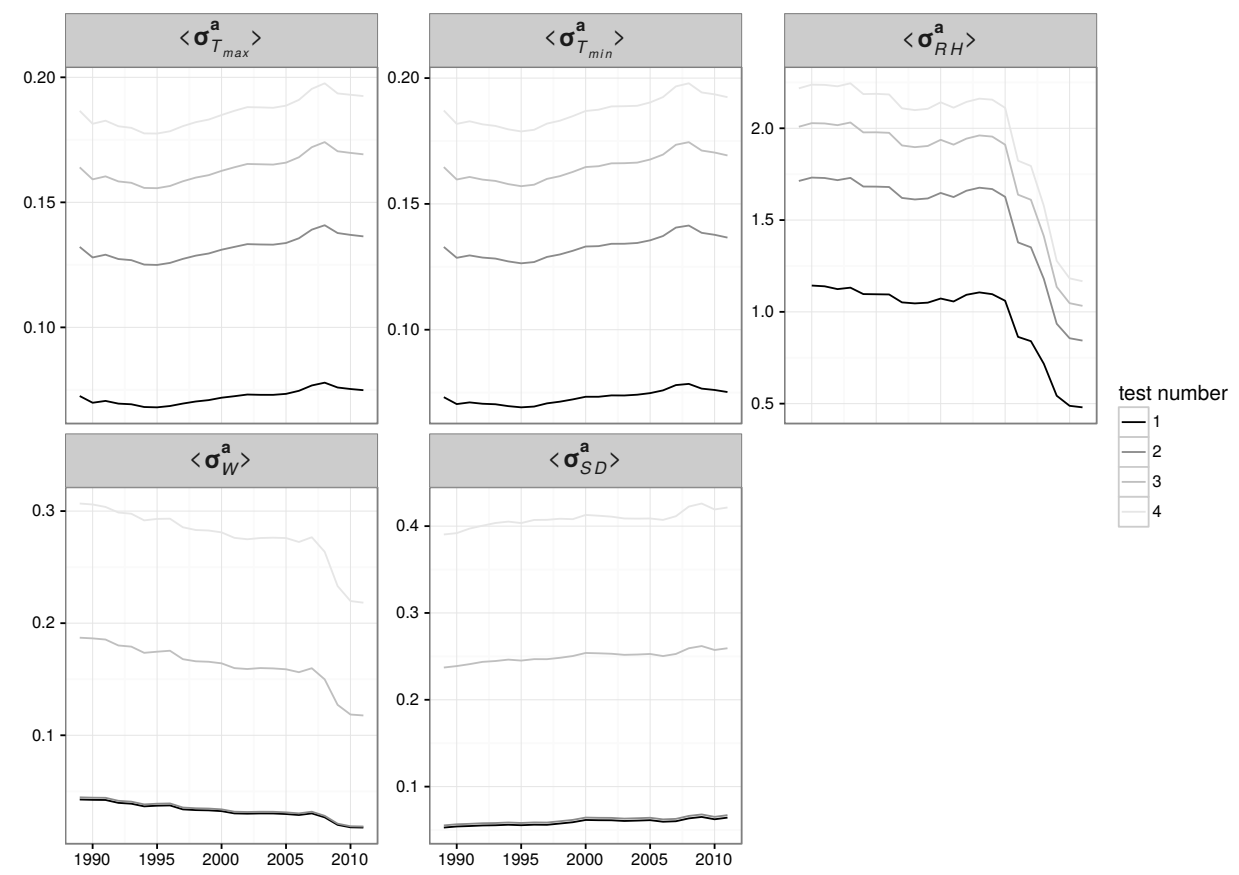

Figure 11: Time series of spatial mean values of uncertainty of each climatic variable $\left(\left\langle\boldsymbol{\sigma}_{v}^{\mathbf{a}}\right\rangle\right)$, as a function of different values of $\beta$. The exact values of $\beta$ for each variable and test number are given in Table 2. 

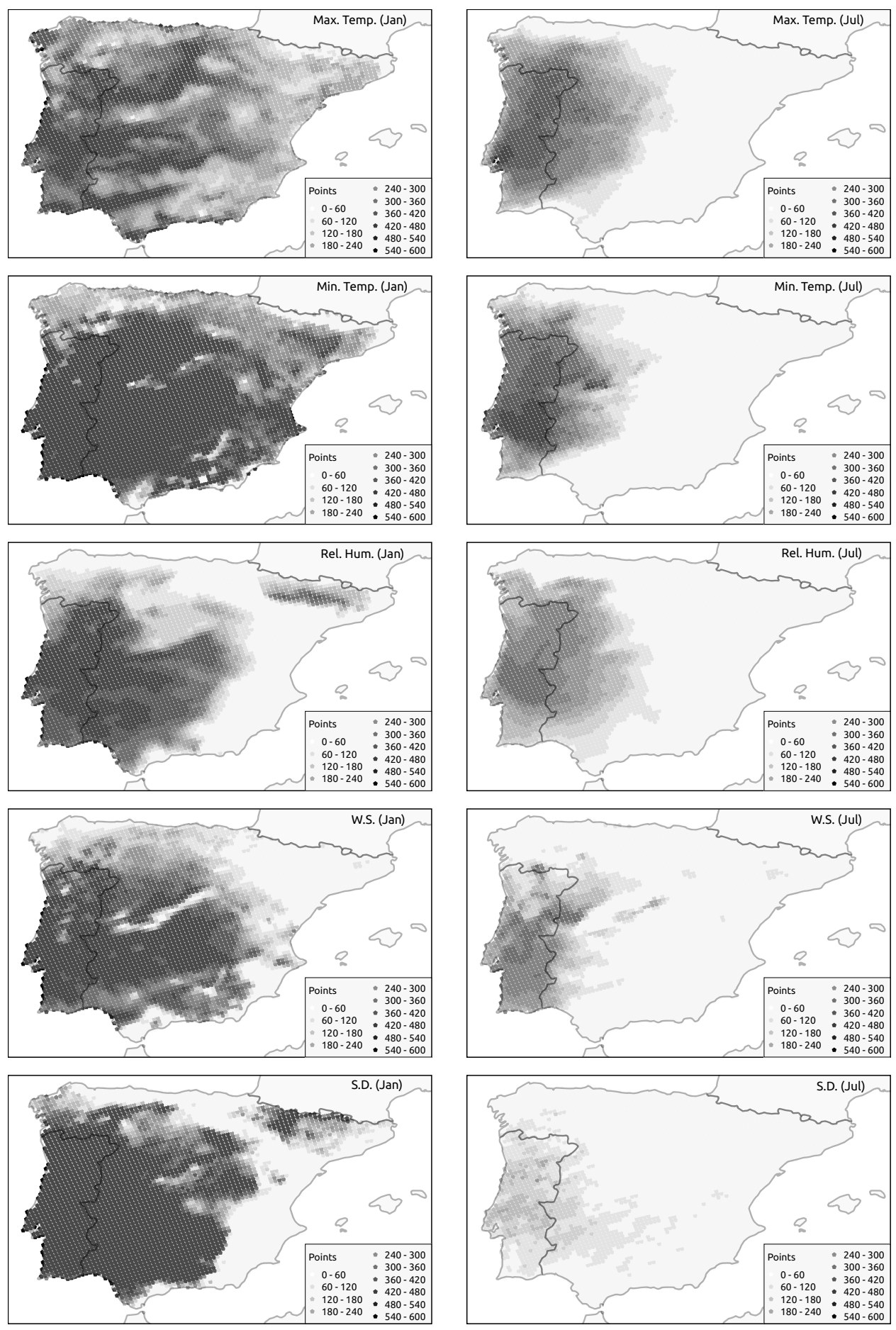

Figure 12: Number of Portuguese grid points for which the correlation coefficient is higher than 0.75 for each grid point in Iberian Peninsula 
${ }_{988}$ Appendix A. Glossary

989 $\mathbf{E T}_{\mathbf{o}}^{a}$ : Reference crop evapotranspiration calculated using meteorological vari-

990 ables estimated by Optimal Interpolation [mm] [dimensions: $m$ ]

${ }_{991} \mathbf{E T}_{\mathbf{o}}^{b}$ : Reference crop evapotranspiration calculated using physically-based cli-

992 mate model data $[\mathrm{mm}]$ [dimensions: $m$ ]

${ }_{993} \mathbf{H}$ : Mask used to map physically-based climate model data into observations

994 data space [dimensions: $n \times m$ ]

995 I: Identity matrix [dimensions $n \times n$ ]

$996 \mathbf{J}_{E T_{o}}$ : Refers to the Jacobian of $\mathbf{E T}_{\mathbf{o}}$ considering only the partial derivatives of

997 climate variables

998 K: Kalman Gain used in the Optimal Interpolation [dimensions: $m \times n$ ]

999 : Number of physically-based climate grid cells $[m=3930]$

$1000 n$ : Number of grid cells containing at least one weather station. Its value varies

1001 for each variable and time step.

${ }_{1002} \mathbf{P}_{v}$ : Error covariance matrix of physically-based climate model variables [di-

1003 mensions: $m \times m]$

${ }_{1004} \mathbf{P}_{v}^{+}$: Posterior error covariance matrix of each climate variable [dimensions:

$1005 m \times m]$

${ }_{1006} \mathbf{Q}_{k}$ : Error covariance matrix of the climate variables at the specific location $k$

1007 [dimensions: $5 \times 5$ ]

${ }_{1008} \mathbf{R}_{v}$ : Error covariance matrix of observations. [dimensions: $n \times n$ ]

${ }_{1009} \mathbf{x}_{v}^{\text {a }}$ : Refers to the Optimal Interpolation climate variable values

${ }_{1010} \mathbf{x}_{v}^{\mathbf{b}}$ : Refers to the Regional Climate Model climate variable values

${ }_{1011} \mathbf{x}_{v}^{\mathrm{t}}$ : Refers to the (unknown) true climate variable values

$1012 \mathbf{y}_{v}$ : Refers to the observed climate variables values

$1013 \sigma$ : Refers to the diagonal positions (the variance) of one of the error covariance

1014 matrix

$1015 \beta$ : Refers to a fix scaling parameter that controls the magnitude of $\mathbf{R}$

$1016 \delta$ : Refers to the analysis differences between the Optimal Interpolation values

${ }_{1017}$ and the Regional Climate Model values $\left(\mathrm{x}^{\mathbf{a}}-\mathrm{x}^{\mathbf{b}}\right)$ 
$1018<\cdot>$ : Refers to the spatial mean of .

$1019 \ll \cdot »$ : Refers to the spatial standard deviation of .

$1020 \because$ : Refers to the temporal mean of .

$1021 \hat{\imath}$ : Refers to the estimated value of .

\section{${ }_{1022}$ Appendix B. Uncertainty trends}

\begin{tabular}{llll}
\hline Month & Tau & 2-sided pvalue & trend $\left(\mathrm{mm}^{2} /\right.$ year $)$ \\
\hline 1 & -0.50 & $8.75 \mathrm{e}-04$ & -0.08 \\
2 & -0.66 & $1.16 \mathrm{e}-05$ & -0.10 \\
3 & -0.62 & $3.00 \mathrm{e}-05$ & -0.17 \\
4 & -0.48 & $1.00 \mathrm{e}-03$ & -0.12 \\
5 & -0.35 & 0.02 & -0.19 \\
6 & -0.17 & 0.24 & -0.18 \\
7 & -0.63 & $2.38 \mathrm{e}-05$ & -0.46 \\
8 & -0.65 & $1.48 \mathrm{e}-05$ & -0.45 \\
9 & -0.43 & $3.60 \mathrm{e}-03$ & -0.18 \\
10 & -0.45 & $2.00 \mathrm{e}-03$ & -0.14 \\
11 & -0.63 & $2.38 \mathrm{e}-05$ & -0.11 \\
12 & -0.66 & $9.12 \mathrm{e}-06$ & -0.10 \\
\hline
\end{tabular}

Table B.3: $E T_{o}$ uncertainty trend 